\title{
Atmospheric evaporative demand observations, estimates and driving factors in Spain (1961-2011)
}

\author{
Cesar $\underline{\text { Azorin-Molina }}{ }^{1}$, Sergio M. Vicente-Serrano ${ }^{1}$, Arturo Sanchez-Lorenzo ${ }^{1}$, Tim R. McVicar ${ }^{2,3}$, \\ Enrique $\underline{\text { Morán-Tejeda }}^{1}$, Jesús $\underline{\text { Revuelto }}^{1}$, Ahmed El Kenawy ${ }^{4,5}$, Natalia Martín-Hernández ${ }^{1}$ and \\ Miquel Tomas-Burguera ${ }^{6}$
}

Surnames (or family names) are underlined

${ }^{1}$ Instituto Pirenaico de Ecología, Consejo Superior de Investigaciones Científicas (IPE-CSIC), Departamento de Procesos Geoambientales y Cambio Global, Zaragoza, Spain

${ }^{2}$ CSIRO Land and Water, Canberra, ACT, Australia

${ }^{3}$ Australian Research Council Centre of Excellence for Climate System Science, Sydney, Australia

${ }^{4}$ Earth System Observations and Modeling Group, WDRC, King Abdullah

University of Science and Technology, Thuwal, Saudi Arabia

${ }^{5}$ Department of Geography, Mansoura University, Mansoura, Egypt

${ }^{6}$ Estación Experimental Aula Dei, Consejo Superior de Investigaciones Científicas (EEAD-CSIC), Zaragoza, Spain

* Corresponding author address: César Azorín-Molina, Instituto Pirenaico de Ecología, Consejo Superior de Investigaciones Científicas (IPE-CSIC), Departamento de Procesos Geoambientales y Cambio Global, Avda. Montañana 1005, 50059-Zaragoza, Spain. E-mail: cazorin@ipe.csic.es

Journal of Hydrology 


\section{Abstract}

We analyzed the spatio-temporal evolution of evaporation observations from Piché atmometers (1961-2011; 56 stations) and Pan evaporimeters (1984-2011; 21 stations) across Spain, and compared both measurements with evaporation estimates obtained by four physical models: i.e., Food and Agricultural Organization-56 Penman-Monteith, Food and Agricultural Organization-Pan, PenPan and Penman, based on climate data. In this study we observed a positive and statistically significant correlation between Piché and Pan evaporation measurements during the common period (1984-2011; 19 stations), mainly in summer. When evaporation observations and estimates were compared, we detected positive and statistically significant correlations with the four methods, except for winter. Among the four physical models, the FAO-Pan showed the best fitting to both Piché and Pan evaporation measurements; the PenPan model overestimated evaporation rates; and the FAO-Penman-Monteith and Penman methods underestimated evaporation observations. We also observed a better spatial agreement between Pan evaporation and estimates than that obtained by Piché measurements. Annual and seasonal trends of evaporation estimates show a statistically significant increase for 1961-2011, which do not agree with long-term Piché evaporation trends; e.g. a discontinuity was found around the 1980s. Radiative and aerodynamic driving factors suggest that this discontinuity, and the observed evaporation trends across Spain could be associated with the abrupt increase in air temperature observed during last few decades (i.e., global warming). Further investigations using available Piché evaporation observations for other regions are needed to better understand physical components influencing long-term trends of evaporation.

Key-words: Piché and Pan observations; evaporation estimations; driving factors; Spain 


\section{Introduction}

Atmospheric Evaporative Demand (AED) is governed by radiative and aerodynamic components (Penman, 1948; McVicar et al., 2012a). The radiative component is related to the available energy to evaporate water, which depends on solar radiation, land surface albedo, air and surface temperatures and vapour pressure. The aerodynamic component is related to the capacity of the air to store water, which is dependent on (i) air temperature given the Classius-Clayperon relationship since water holding capacity of air increases by about $7 \%$ per $1^{\circ} \mathrm{C}$ of warming, (ii) vapour pressure deficit (VPD) as the difference between the amount of moisture in the air and how much moisture the air can hold when it is saturated, and (iii) wind speed which moves the saturated air and brings unsaturated air to continue evaporating (i.e., if energy and water are available and the incoming air is not saturated).

Observations show that AED has contrasting trends among regions and periods as a consequence of the evolution of the different climate factors that control this variable (e.g., Hidalgo et al., 2005; Cong et al., 2009; Liu et al., 2011; McVicar et al., 2012b). Some studies suggest that the observed changes in AED are related to changes in the VPD, mainly in semi-arid regions (Wang et al., 2011). While others show that the effect of climate warming on AED is minimal, and the evolution of other meteorological variables (primarily solar radiation and wind speed) are more important to explain the observed changes (Roderick and Farquhar, 2002; Jhajharia et al., 2006 and 2009a; Roderick et al., 2007; McVicar et al., 2012b).

Despite observed climate warming, numerous studies assessing observed Pan evaporation $\left(E_{P a n}\right)$ trends have shown a general decrease in $E_{\text {Pan }}$ has been widely reported (e.g., Peterson et al., 1995; Roderick and Farquhar, 2004; McVicar et al., 2012b, their Table 5). Different hypotheses have been formulated to explain the $\mathrm{E}_{\text {Pan }}$ decrease under global warming, including decreased solar radiation (Stanhill and Cohen, 2001; Roderick and Farquhar, 2002; Matsoukas et al., 2011), a widespread decline in near-surface wind speed (McVicar et al., 2012b) or both together (Jhajharia et 
al., 2009a). Brutsaert (2006) and McVicar et al. (2012a) stressed that current AED trends are likely not linked to a individual process, yet are more likely attributed to simultaneous changes in the primary meteorological variables governing the evaporation process: solar irradiance, air temperature, relative humidity and wind speed.

There is strong scientific and social interest to know how AED is changing given the current climate change scenario (including global warming), given the far-reaching hydrological, agricultural and environmental implications. Nevertheless, there are few studies that have compared trends in Evaporation (E) observations (using $E_{\text {Pan }}$ measurements) and estimations (by means of physical models that use data of VPD, air temperature, solar radiation and wind speed) (e.g., Chattopadhyay and Hulme, 1997; Hobbins et al., 2004; Abtew et al., 2011; Johnson and Sharma, 2007 and 2010). These types of studies are highly relevant since the agreement between observations and physical estimates provides more robustness when determining evaporation variability and trends. Moreover, they can provide knowledge on how changes in the primary meteorological variables may affect AED trends in the current climate change scenario.

The Mediterranean region is one of the hotspot areas of the world in relation to climate change processes and their impact on water resources availability. For instance, a consistent decrease in water resources has been identified in recent decades (García-Ruiz et al., 2011). This has been primarily related to decreasing precipitation and increasing temperature trends across the Mediterranean region. Nevertheless, the analysis of the relationship between increasing air temperature and AED processes in the region has been poorly assessed and no AED observations have been analyzed, with the exception of Turkey (Topaglou et al., 2012; Yesilirmak, 2013), Israel (Cohen et al., 2002) and Greece (Papaioannou et al., 2011). To date, there are no studies assessing AED trends using observations in the western Mediterranean basin.

In this study, we analyse the evolution of AED observations and estimations across Spain from 1961 to 2011. In this region, AED is highly relevant for agriculture, forestry and water 
resources (e.g., Austin et al., 1998; Estrela et al., 2012). Moreover, air temperature over this region has increased $2^{\circ} \mathrm{C}$ in the last five decades (Brunet et al., 2007; Vicente-Serrano et al., 2014a), relative humidity and cloud cover have experienced a strong decrease during the same period (VicenteSerrano et al., 2014a; Sanchez-Lorenzo et al., 2012), whereas wind speed (Azorin-Molina et al., 2014) and solar radiation (Sanchez-Lorenzo et al., 2007) have not shown a clear trend. Different ecological studies have hypothesized that increased AED is in the root of the decline in forest growth (Carnicer et al., 2011), and the increase of degradation processes in vulnerable semi-arid areas (Vicente-Serrano et al., 2012). The objectives of this study are threefold: (i) to determine the spatial relationship between the AED observed and estimated by four physical models based on climate information; (ii) to assess the temporal relationship and consistency between AED observations by different instruments and estimations for 1961-2011; and (iii) to quantify the influence of variability of the primary meteorological variables (i.e., air temperature, relative humidity, wind speed and solar radiation) on the AED evolution in Spain.

\section{Meteorological datasets}

We used daily time series of near-surface meteorological variables observed at 56 meteorological stations from the Spanish State Meteorological Agency (AEMET), including: (i) AED observations from (a) Class-A Pan evaporimeters, and (b) Piché atmometers; and (ii) meteorological data such as atmospheric pressure, relative humidity, wind speed, air temperature and sunshine duration, to estimate E using four physical models (see subsection 3.1).

Among the different approaches to directly measure E (e.g., lysimeters, eddy covariance towers, etc.; McMahon et al., 2013), pan evaporation is the most widely used instrument (Roderick et al., 2009; Fu et al., 2009; Stanhill, 2002). Class-A Pan evaporimeters are circular cylinders of $120 \mathrm{~cm}$ diameter and $25 \mathrm{~cm}$ depth, mounted on an open wooden platform. The pan is filled with water to 20 cm depth, and the daily evaporation rate, adjusted for precipitation, is measured manually. The USA 
Class-A evaporator is the most widely used pan (for more details see Roderick et al., 2009), and has been used at AEMET's first-order meteorological stations since 1984.

Much less used is the Piché atmometer (Papaioannou et al., 1996), which consists of a $3 \mathrm{~cm}$ diameter disc of filter paper held by a metal clip to the bottom of an inverted graduated cylindrical tube of $1.5 \mathrm{~cm}$ in diameter, which supplies deionized water to the disc. The water is evaporated from the surface of the filter paper and daily measurements of the volume of water remaining in the graduated tube allow to compute evaporation (in mm). In Spain, the Piché atmometer is located inside Stevenson screens together with other meteorological instruments. Observations of Piché (E $\left.E_{\text {Piché}}\right)$ and Pan ( $\left.E_{\text {Pan }}\right)$ evaporation were obtained from Sanchez-Lorenzo et al. (2014): EPiché are observed at 56 stations for 1961-2011, and E Pan $_{\text {are observed at }} 21$ stations for 1984-2011. Both EPiché and $\mathrm{E}_{\mathrm{Pan}}$ series were carefully quality controlled and homogenized (for details see Sanchez-Lorenzo et al., 2014). E Piché $_{\text {and }} E_{\text {Pan }}$ were simultaneously observed at 19 locations for the common period 1984-2011.

Only AEMET’s first-order meteorological stations (approximately 100) measure all the required variables to estimate AED. Using these records and after applying a homogenization protocol, high quality controlled and homogeneous time series were created by Sanchez-Lorenzo et al. (2007) of monthly sunshine duration for the Iberian Peninsula since 1900; Vicente-Serrano et al. (2014a) of monthly relative humidity (also maximum and minimum air temperature and atmospheric pressure) across Spain since the 1960s; and Azorin-Molina et al. (2014) of monthly near-surface (10-m height) wind speed dataset for Spain and Portugal since 1961. We updated (until 2011 in case of sunshine duration) and used these reliable datasets to estimate AED in Spain.

Figure 1 shows the location of the stations used and the availability of data at each station. In 32 out of 56 stations with $E_{\text {Piché }}$ and in 12 out of 21 stations with $E_{\text {Pan }}$ there were also meteorological data to compare between evaporation observations $\left(E_{\mathrm{Obs}}\right)$ and evaporation estimates $\left(\mathrm{E}_{\mathrm{Est}}\right)$. Only in 
10 first-order meteorological stations were $E_{\text {Piché, }} E_{\text {Pan }}$ and the required meteorological data simultaneously observed.

\section{Methods}

\subsection{Atmospheric evaporative demand methods}

There are different models to estimate AED using meteorological data (see McMahon et al., 2013). We used four physical models corresponding to different modifications of the method proposed by H.L. Penman (1948), who developed a theoretical approach to estimate E from saturated surfaces based on combining both aerodynamic and radiative components.

\subsubsection{FAO-56 Crop Reference ET}

Monteith (1965) extended the formulation of Penman (1948) by introducing resistance factors to estimate evapotranspiration from vegetated surfaces. The Food and Agricultural Organization-56 Penman-Monteith (FAO-PM) method was developed by defining key parameters for a reference crop with: (i) a height of $0.12 \mathrm{~m}$; (ii) a surface resistance of $70 \mathrm{~s} \mathrm{~m}^{-1}$; (iii) an albedo of 0.23 ; and (iv) actively growing and non-water limited green grass (Allen et al., 1998). Although this approach is focused on evapotranspiration and not direct evaporation from water surfaces, we have also included it in our analysis given that it is currently the most widely used and accepted formulation to determine AED (Allen et al., 1998; Walter et al., 2000). The FAO-56 PM evapotranspiration is:

$$
E T_{o}=\frac{0.408 \Delta\left(\mathrm{R}_{\mathrm{n}}-\mathrm{G}\right)+\gamma \frac{900}{\mathrm{~T}+273} u_{2}\left(e_{s}-e_{a}\right)}{\Delta+\gamma\left(1+0.34 u_{2}\right)}
$$

$\mathrm{ET}_{\mathrm{o}}$ is the daily crop reference evapotranspiration $\left(\mathrm{mm} \mathrm{day}^{-1}\right), T$ is the mean air temperature at a height of $2 \mathrm{~m}\left({ }^{\circ} \mathrm{C}\right), R_{n}$ is the net radiation, which is dependent on the surface albedo $\left(\mathrm{MJ} \mathrm{m}^{-2}\right.$ day $\left.^{-1}\right)$, $G$ is the soil heat flux density $\left(\mathrm{MJ} \mathrm{m}^{-2}\right.$ day $\left.^{-1}\right), \gamma$ is the psychrometric constant $\left(\mathrm{kPa}^{\circ} \mathrm{C}^{-1}\right), \mathrm{u}_{2}$ is the wind speed at $2 \mathrm{~m}$ height $\left(\mathrm{m} \mathrm{s}^{-1}\right), \mathrm{e}_{\mathrm{s}}$ is the saturation vapour pressure $(\mathrm{kPa}), \mathrm{e}_{\mathrm{a}}$ is the actual vapour pressure $(\mathrm{kPa})$, and $\mathrm{e}_{\mathrm{s}}-\mathrm{e}_{\mathrm{a}}$ is the saturation vapour pressure deficit $(\mathrm{kPa})$. 


\subsubsection{FAO-Pan evaporation}

Allen et al. (1998) used $\mathrm{ET}_{0}$ to estimate Pan evaporation by applying an empirically derived pan coefficient:

$$
E_{F A O-P a n}=\frac{E T_{o}}{K_{p}}
$$

where $E_{\text {FAO-Pan }}$ is the pan evaporation $\left(\mathrm{mm} \mathrm{day}^{-1}\right)$ and $\mathrm{K}_{\mathrm{p}}$ is a pan coefficient, which depends on the types Pan evaporimeters and environments (Allen et al., 1998; McVicar et al., 2007). According to the conditions in which the Class-A Pans are installed and maintained by the AEMET, a green fetch of $1000 \mathrm{~m}$ is considered to calculate $\mathrm{K}_{\mathrm{p}}$ according to the following equation (Allen et al., 1998):

$$
K_{p}=0.108-0.0286 u_{2}+0.422 \ln (1000)+0.1434 \ln (R H)-0.000631\left[\ln (1000)^{2} \ln (R H)\right]
$$

where $\mathrm{RH}$ is relative humidity.

\subsubsection{PenPan model}

Rotstayn et al. (2006) coupled the radiative component of Linacre (1994) and the aerodynamic component of Thom et al. (1981) to develop the PenPan model (note the two capital Ps to differentiate it from Linacre’s (1994) contribution). It estimates monthly and annual Class-A pan evaporation (see also Roderick et al., 2007; Johnson and Sharma, 2010). According to Rotstayn et al. (2006), PenPan is defined as:

$$
E_{\text {PenPan }}=\frac{\Delta}{\Delta+2.4 \gamma} \frac{R_{N P a n}}{\lambda} f_{\text {Pan }}(u)\left(e_{s}-e_{a}\right)
$$

where $E_{\text {PenPan }}$ is the pan evaporation $\left(\mathrm{mm} \mathrm{day}^{-1}\right)$ by the PenPan model, $f_{\text {Pan }}(u)=1.202+1.62 u_{\mathbf{2}}$, and $R_{\text {Npan }}$ is the net radiation at the Class-A Pan evaporimeters, the calculation of which is provided in the Supplementary Material 6 of McMahon et al. (2013). A high general agreement between $E_{\text {Pan }}$ observations and $E_{\text {PenPan }}$ calculations in a number of stations in Australia (Roderick et al., 2007; McMahon et al., 2013) and China (Liu et al., 2011; Yang and Yang, 2012). 


\subsubsection{Penman evaporation model}

Penman (1948) combined the energy balance with the mass transfer methods to derive an equation to compute the E from an open water surface, based on standard meteorological records of solar radiation, air temperature, relative humidity and wind speed. The Penman model is defined as follows (Penman, 1948, see also McMahon et al., 2013):

$$
E_{P e n}=\frac{\frac{\Delta\left(R_{n}-G\right)}{\lambda}}{\Delta+\gamma}+\gamma E_{a}
$$

where $E_{\text {Pen }}$ is the daily potential evaporation in $\mathrm{mm} \mathrm{day}^{-1}, \Delta$ is the slope vapor pressure curve (dependent on air temperature) $\left(\mathrm{kPa}^{\circ} \mathrm{C}^{-1}\right), R_{n}$ is the net radiation, which is dependent on the surface albedo ( $\mathrm{MJ} \mathrm{m}^{-2}$ day $^{-1}$ ) and obtained according to Allen et al. (1998) using sunshine duration as input, $G$ is the soil heat flux density $\left(\mathrm{MJ} \mathrm{m}^{-2} \mathrm{day}^{-1}\right), \gamma$ is the psychrometric constant $\left(\mathrm{kPa}^{\circ} \mathrm{C}^{-1}\right), \lambda$ is the latent heat of vaporization $\left(\mathrm{MJ} \mathrm{kg}^{-1}\right)$ and $\mathrm{E}_{\mathrm{a}}$ is the isothermal evaporation rate $\left(\mathrm{kg} \mathrm{m}^{-2} \mathrm{~s}\right)$, which depends on daily wind speed, saturation vapour pressure and average vapour pressure.

Shuttleworth (1992) modified and adapted the Penman equation to use SI units, which made its calculation much simpler:

$$
E_{\text {Pen }}=\frac{\Delta R_{n}+\gamma 6.43\left(1+0.536 u_{2}\right)\left(e_{s}-e_{a}\right)}{\lambda(\Delta+\gamma)}
$$

where $u_{2}$ is the wind speed at $2 \mathrm{~m}$ height $\left(\mathrm{m} \mathrm{s}^{-1}\right), e_{s}$ is the saturation vapour pressure $(\mathrm{kPa}), \mathrm{e}_{\mathrm{a}}$ is the actual vapour pressure $(\mathrm{kPa})$, and $\mathrm{e}_{\mathrm{s}}-\mathrm{e}_{\mathrm{a}}$ is the saturation vapour pressure deficit $(\mathrm{kPa})$. We have used this modified equation to estimate potential E; this has also recently used in Australia (Donohue et al., 2010) and China (Liu and McVicar, 2013; Wang et al., 2013).

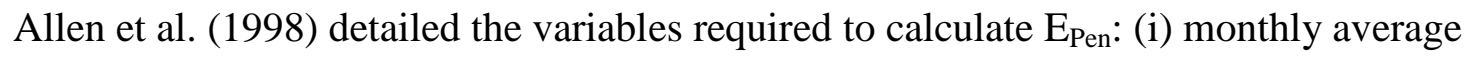
maximum and minimum air temperatures $\left({ }^{\circ} \mathrm{C}\right)$; (ii) monthly average actual vapour pressure $\left(\mathrm{e}_{\mathrm{a}}\right.$; $\left.\mathrm{kPa}\right)$; (iii) average monthly net radiation $\left(\mathrm{MJ} \mathrm{m}^{-2} \mathrm{day}^{-1}\right)$; and (iv) monthly average wind speed $\left(\mathrm{m} \mathrm{s}^{-1}\right)$ 
measured at $2 \mathrm{~m}$ above ground level. Among these $\mathrm{e}_{\mathrm{a}}$ is not measured at meteorological stations, yet can be readily calculated from relative humidity and air temperature (Allen et al., 1998; see page 39). Of the other necessary variables, monthly average net solar radiation $\left(R_{n}\right)$ is not commonly available from meteorological stations, and generally few and only short time series of surface solar radiation are available in Spain (Sanchez-Lorenzo et al., 2013). However, this variable is commonly estimated from the monthly averages of daily sunshine hours, measured using Campbell-Stokes sunshine duration recorders. Thus, $\mathrm{R}_{\mathrm{n}}$ was obtained using estimates of solar radiation (Rs) by means of extraterrestrial radiation, relative sunshine duration (Allen et al., 1998; see page 50) and the parameters $a_{s}=0.25$ and $b_{s}=0.50$. The comparison of estimates and observations of incoming Rs at six available stations from the 1980s (see Sanchez-Lorenzo et al., 2013), shows a strong ( $r 2>0.98$ ) agreement both for monthly long-term averages and monthly values (see Supplementary Figures 1 and 2). In addition, soil heat flux (G) was estimated using monthly mean air temperatures (Allen et al., 1998; see page 54). The $\gamma$ was obtained using atmospheric pressure (kPa) (Allen et al., 1998; see page 32); and mean saturation pressure $\left(\mathrm{e}_{\mathrm{s}}\right)$ and the slope of saturation vapour pressure curve $(\Delta)$ were obtained from monthly maximum and minimum air temperatures (Allen et al., 1998; see pages 36 and 37); and near-surface wind speed data commonly measured at $10 \mathrm{~m}$ above the ground were adjusted to 2 m by applying a logarithmic relationship (Allen et al., 1998; see page 55).

\subsection{Analysis of the spatial relationship between AED observations ( $\left.E_{\text {Obs }}\right)$ and estimations $\left(E_{E s t}\right)$}

We compared the spatial agreement between the average annual and seasonal series of $E_{\mathrm{Pan}}$ and $E_{\text {Piché. }}$ The relationship between average annual and seasonal $E_{O b s}$ and $E_{E s t}$ by the four physical models was assessed by means of a set of accuracy/error statistics (Willmott, 1982) including: (i) mean bias error (MBE), which indicates the average over- or under-estimation; and (ii) mean absolute error (MAE), which is a measure of the average error of the estimation. The seasons were 
defined as winter (December, January and February), spring (March, April and May), summer (June, July and August) and autumn (September, October and November).

\subsection{Analysis of temporal trends and relationships between AED observations ( $\left.E_{O b s}\right)$ and estimations $\left(E_{E s t}\right)$}

A non-parametric (Mann-Kendall tau) test was used to analyse the temporal trends in the AED time series. This method is more robust than parametric coefficients and does not assume normality of datasets (Lanzante, 1996). Tau values measure the degree to which a trend is consistently increasing or decreasing. Throughout this paper statistically significant trends were defined as those having a significance level of $p<0.05$. To assess the magnitude of change we used a regression analysis between the series of time (independent variable) and the evaporation series (dependent variable). The slope of the regression line indicates the change (evaporation change per year).

Temporally the $E_{\text {Obs }}$ measures of $E_{\text {Piché }}$ and $E_{\text {Pan }}$ were correlated with $E_{E s t}$ obtained from the four physical models to determine the temporal agreement between $\mathrm{E}_{\mathrm{Obs}}$ and $\mathrm{E}_{\mathrm{Est}}$. Correlations were calculated annually and seasonally. To check possible changes in the relationship between $\mathrm{E}_{\mathrm{Obs}}$ and $E_{E s t}$, we used the Standard Normal Homogeneity Test (SNHT, Alexandersson, 1986). This method estimates, with a confidence level, the existence of a break in the relationship between two time series by means of a statistic $\mathrm{T}_{\mathrm{i}}$ (i.e. test statistic for the ordinary $t$-test) obtained from a combined sequential calculation of the average values of both series.

\subsection{Analysis of the influence of climate variability on the AED evolution}

We related the evolution of $E_{\text {Piché }}$ and $E_{\text {Pan }}$ with relative humidity, mean air temperature, wind speed and solar radiation by means of correlation and regression analyses. We also checked possible changes in the relationship between the evolution of $E_{\text {Piché }}$ and these climate variables by the SNHT (described above). We used the sequential Mann-Kendall test (Sneyers, 1975; Esteban-Parra et al., 
1998) to detect the beginning of the trend within each climate variable. This test sets up two series, a progressive one $u(t)$ and a backward one $u^{\prime}(t)$. If they diverge beyond the specific threshold value (i.e., $5 \%$ significant level), then there is a statistically significant trend. The point where they cross each other indicates the approximate year at which there is a change-point in the climate series. Finally, the most probable date of change in the series were determined by the Bai and Perron test (2003), which is a breakpoint test for the coefficients in a least-square model. Finally, we created a simple predictive linear regression model with the annual and seasonal $\mathrm{E}_{\mathrm{FAO}-\mathrm{Pan}}$ regional series as the independent variable and the associated annual and seasonal EPiché as dependent variable. The series of residuals of the model (the difference between observed and estimated evaporation using $\mathrm{E}_{\mathrm{FAO} \text {-Pan }}$ as predictor) were related to the evolution of wind speed, relative humidity and solar radiation.

\section{Results}

\subsection{Piché vs. Pan evaporation}

We found strong agreement between the annual and seasonal regional EPiché and $E_{\text {Pan }}$ series for all Spain for the common period 1984-2011, mainly from spring to autumn (Figure 2). In winter this agreement is low, probably because of problems encountered when using Class-A Pan evaporimeters during this season; e.g., the formation of frost/ice. These winter discrepancies are not very representative since evaporation is much lower than that observed in other seasons. There are no clear spatial patterns in annual and seasonal correlations between $E_{\text {Piché }}$ and $E_{\text {Pan, }}$ although near the Mediterranean Sea correlations are lower than those found in South and Inner areas of Spain (Supplementary Fig. 3). Magnitude of correlations between $E_{\text {Piché }}$ and $E_{\text {Pan }}$ for each of the 19 stations is lower than that observed in the regional series in Fig. 2. However, in the majority of the stations the correlations are positive and statistically significant both annually and seasonally (Figure 3).

\subsection{Spatial relationship between $A E D$ observations $\left(E_{O b s}\right)$ and estimations $\left(E_{E s t}\right)$}


The spatial distribution of the average annual $E_{\text {Piché, }} E_{\text {Pan }}$ and $E_{\text {Est }}$ shows a good agreement, with, as expected, different magnitudes amongst $\mathrm{E}_{\mathrm{Est}}$ calculated by the four physical models. Spatial distribution shows that $\mathrm{E}_{\mathrm{Obs}}$ and $\mathrm{E}_{\mathrm{Est}}$ are higher in the South when compared to the Atlantic and Mediterranean coastlands and the North (Supplementary Fig. 4). Comparing the spatial distribution of the average annual and seasonal $E_{\text {Piché }}$ with the average $E_{E s t}$, the coefficients of determination oscillate between 0.42 and 0.69 , depending on the $\mathrm{E}_{\mathrm{Est}}$ method and season (Figure 4). In general, the four estimation methods show a similar behaviour for annual and seasonal averages. $\mathrm{ET}_{\mathrm{o}}$ shows lower values than $E_{\text {Piché }}$ whereas $E_{\text {PenPan }}$ shows higher values. Nevertheless, independent of the $E_{E s t}$ model, they tend to underestimate $\mathrm{E}$ in areas with high $\mathrm{E}_{\text {Piché }}$ Observation. In contrast, the $\mathrm{E}_{\mathrm{FAO} \text {-Pan, }}$ $E_{P e n P a n}$ and $E_{P a n}$ overestimate annual and seasonal evaporation rates in areas of low EPiché. Agreement between $\mathrm{E}_{\mathrm{Obs}}$ and $\mathrm{E}_{\mathrm{Est}}$ is better considering $\mathrm{E}_{\mathrm{Pan}}$ (Figure 5). Although the different models overestimate $\mathrm{E}$ in relation to average $\mathrm{E}_{\mathrm{Pan}}$, the coefficients of determination are higher for $\mathrm{E}_{\mathrm{Pan}}$ than those found for EPiché, mainly in summer months.

\subsection{Temporal trends and relationships between $A E D$ observations ( $\left.E_{O b s}\right)$ and estimations ( $\left.E_{E s t}\right)$}

The agreement between the monthly EPiché, $E_{\text {Pan }}$ and $E_{E s t}$ by the four physical models at individual stations is high (Supplementary Fig. 5). Specifically, monthly correlations of $E_{\text {Est }}$ with $E_{\text {Piché }}$ at the 32 stations is high (i.e., Pearson's $r$ oscillates between 0.81 and 0.83 ), showing few differences among the four estimation methods. Scatterplots reveal that $\mathrm{ET}_{\mathrm{o}}$ and $\mathrm{E}_{\mathrm{Pan}}$ generally show lower values than monthly E Eiché whereas $E_{F A O-P a n}$ and $E_{\text {PenPan }}$ models show better agreement with the monthly $E_{\text {Obs. }}$ The relationship between monthly $\mathrm{E}_{\mathrm{Pan}}$ and $\mathrm{E}_{\mathrm{Est}}$ is stronger than that found for E Eiché (Supplementary Fig. 5); the coefficients of correlation oscillate between 0.91 and 0.93 depending on the method, and again, $\mathrm{E}_{\mathrm{PenPan}}$ and especially the $\mathrm{E}_{\mathrm{FAO}-\mathrm{Pan}}$ models show a better agreement with $\mathrm{E}_{\mathrm{Obs}}$. In addition, when averaging all monthly $\mathrm{E}_{\mathrm{Est}}$ and $\mathrm{E}_{\mathrm{Obs}}$ the strength of the relationship between $\mathrm{E}_{\mathrm{Pan}}$ and $\mathrm{E}_{\text {Piché }}$ and 
$E_{\text {Est }}$ is increased noticeably (Supplementary Fig. 6). Thus, the Spanish monthly average $E_{F A O-P a n}$ shows a strong agreement with the magnitude of the Spanish monthly records of both $E_{\text {Piché }}$ and E $E_{\text {Pan }}$.

We also found that monthly correlations between $E_{O b s}$ and $E_{E s t}$ are lower than that found for seasonal time scales. The correlations at the stations are in general statistically significant for $\mathrm{E}_{\text {Piché, }}$ both annually and seasonally. Moreover, $\mathrm{E}_{\text {Est }}$ shows the same correlation with annual and seasonal $E_{\text {Piché }}$ (Figure 6). This means that the four physical methods to estimate AED are recording the same temporal variability, and they are only showing differences in the magnitude of $\mathrm{E}_{\mathrm{Est}}$. The correlation between annual and seasonal series of $\mathrm{E}_{\text {Est }}$ Oscillates between 0.98 and 0.99 at individual stations. Thus, selecting one of these methods is sufficiently representative to approximately estimate AED seasonality in Spain. Correlations between annual and seasonal $E_{\text {Piché }}$ and $E_{E s t}$ show similar spatial patterns and magnitude, independent of the method used (Supplementary Fig. 7). The same is found with correlations between annual and seasonal $\mathrm{E}_{\text {Pan }}$ and $\mathrm{E}_{\mathrm{Est}}$ (Figure 7; Supplementary Fig. 8).

The Spanish average annual and seasonal Epiché shows strong agreement with the corresponding average $\mathrm{E}_{\mathrm{Est}}$ (Figure 8). Temporal variability of $\mathrm{E}_{\mathrm{Est}}$ is quite similar, and only shows differences of magnitude. The E Eiché evolution for all Spain shows more agreement with $\mathrm{E}_{\mathrm{FAO} \text {-Pan }}$ annually. Nevertheless, in terms of magnitude it shows more agreement with EPenPan in winter and autumn, whereas it agrees more with $\mathrm{E}_{\mathrm{Pan}}$ in spring and summer. Regional correlation is strong, independent of the method used to obtain $\mathrm{E}_{\mathrm{Est}}$ in spring, summer and autumn (Table 1). Temporal variability of the Spanish regional annual and seasonal $\mathrm{E}_{\text {Pan }}$ also shows strong agreement with $\mathrm{E}_{\mathrm{Est}}$, with the exception of winter (Supplementary Fig. 9 and Table 1). This stresses that using either one of the four Penman-based equations, an accurate representation of the temporal variability and long term trends of AED in Spain is obtained (Table 2).

We also observed that the Spanish regional series in Figure 8 show higher agreement between $E_{\text {Piché }}$ and $\mathrm{E}_{\mathrm{Est}}$ from the beginning of the 1980s. Thus, there is a clear break in the relationship between $\mathrm{E}_{\mathrm{Obs}}$ and $\mathrm{E}_{\mathrm{Est}}$ at the beginning of this decade. Figure 9 shows the evolution of the SNHT $\mathrm{T}_{0}$ 
statistic considering, as the candidate series, the regional annual and seasonal series of Epiché for all

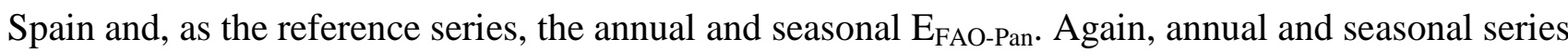
show a marked discontinuity at the beginning of the 1980s, which cannot be attributed to the changes in Piché atmometers (AEMET personal communication, 2014). Moreover, given the simplicity of this evaporimeter, it seems difficult to consider an inhomogeneity at the regional level due to observational practices, since the evaporation time series were previously carefully quality controlled and homogenized using pair-wise comparisons (Sanchez-Lorenzo et al., 2014).

This observed temporal breakpoint affected the magnitude of AED changes. Thus, the regional EPiché shows an increase of $5.25 \mathrm{~mm}_{\text {decade }}{ }^{-1}$ over 1961-2011 (Table 2). The increase is not statistically significant. In contrast, the regional four physical methods of $E_{E s t}$ all displayed a high increase of annual evaporation (from 23 to $39 \mathrm{~mm}^{\text {decade }}{ }^{-1}$ ); all are statistically significant. A significant E Piché increase is only identified in summer, but the magnitude of change is much lower than that identified

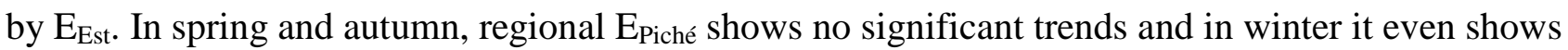
a significant decrease.

\subsection{Influence of climate variability on the AED evolution}

Supplementary Fig. 10 shows a boxplot with correlations between E $E_{\text {Piché }}$ (1961-2011) and E Ean (19842011) with meteorological variables in the different stations (see spatial patterns in Supplementary Figs. 11 and 12). The pattern of correlation with the climate variables is similar for $E_{\text {Piché }}$ and $E_{\text {Pan, }}$ both annually and seasonally. Annually, the majority of stations show a significant and negative correlation with relative humidity for both $E_{\text {Piché }}$ and $E_{\text {Pan. }}$ In spring, summer and autumn the pattern and magnitude of correlations are quite similar. For instance, correlations with wind speed are dominantly non-significant whereas for relative humidity about $90 \%$ of the stations show negative and significant correlations. Additionally, air temperature and solar radiation also show dominant positive and significant correlations at the majority of stations. This suggests that changes in these 
variables (i.e., relative humidity, solar radiation and air temperature) may affect the observed breakpoint in the relationship between $\mathrm{E}_{\mathrm{Obs}}$ and $\mathrm{E}_{\mathrm{Est}}$ detected in the 1980s. In winter, correlations of $E_{\text {Piché }}$ and $E_{\text {Pan }}$ with the climate variables are non-significant, with only exception of relative humidity.

Equally, there is a strong relationship between regional series of EPiché and the regional series of relative humidity, mean air temperature, and solar radiation. Correlations are high between $\mathrm{E}_{\text {Piché, }}$ relative humidity and solar radiation for spring, summer and autumn (Figure 10). Correlation is negative with relative humidity and positive with solar radiation. The magnitude of correlations with these climate variables are quite similar whereas correlation with mean air temperature is lower, with the exception of summer. Wind speed has lower influence to explain variability in EPiché. At the annual scale, correlation between $E_{\text {Piché }}$ and solar radiation is stronger than with relative humidity. Thus, correlation with independent variables is similar to that found between $E_{\text {Piché }}$ and the different $\mathrm{E}_{\text {Est }}$ (Table 1). Moreover, the correlation magnitude between $\mathrm{E}_{\text {Piché }}$ and the different climate variables is similar to that observed with $E_{\text {Pan }}$ series for 1984-2011 (Supplementary Fig. 13). For Spain, we found that relative humidity is the most important variable to explain temporal variability of $\mathrm{E}_{\text {Pan }}$ in spring, summer and autumn. On the contrary, correlation with solar radiation is lower than that found for $E_{\text {Piché }}$ for 1961-2011. Correlation between $E_{\text {Pan }}$ and temperature is positive and significant for summer and autumn and negative in winter. The correlations of EPiché with climate variables for 1984-2011 period, when $E_{P a n}$ is available, are similar to those encountered for $E_{P a n}$ and equivalent to those found for the whole period 1961-2011. Nevertheless, correlation with relative humidity is much stronger for the shorter period than that found for the entire longer period (Supplementary Table 1).

The evolution of annual and seasonal spring, summer and autumn series of $E_{\text {Piché }}$ displays a strong relationship with the variability of solar radiation (Figure 11). Thus, there are no appreciable changes in the temporal relationship between $E_{\text {Piché }}$ and solar radiation during 1961-2011. The SNHT 
applied considering solar radiation as the reference series and Epiché as the candidate series does not show a significant break around 1980-1982 (Supplementary Figure 14). The evolution of regional E$_{\text {Piché }}$ and regional relative humidity shows a clear inverse relationship (Figure 11), yet there is no clear break point in the relationship between the series during 1961-2011. The main discontinuity is found in summer around 2000, coinciding with a sharp decrease in relative humidity during the last decade. Analyzing the relationship between annual and seasonal $E_{\text {Piché }}$ and mean air temperature (Fig. 11), we found a marked discontinuity in the relationship of both series around 1980-82, which is evident both annually and seasonally. Thus, the SNHT shows a significant break between the evolution of both series around 1980 annually and at seasonally for winter, spring and autumn.

Application of a sequential Mann-Kendall test to determine trends in climate series, and the Bai \& Perron test to determine the most probable change points in the series, show that the all-Spain series for both annual relative humidity and mean air temperature have a significant break in the 1980s, which coincides with the commencement of the decreased tendency of relative humidity and the increased trend of air temperature (Figure 12). Moreover, this test does not find a noticeable break and trend change in the solar radiation and wind speed series in the 1980s.

The residuals of the model show a discontinuity around 1980-82 in all four seasons, varying from positive residuals between 1961 and 1982 to negative residuals for 1982 until 2011 (Figure 13). The comparison of the evolution of model residuals with annual and seasonal relative humidity, solar radiation and mean air temperature shows that the strong decrease in model residuals in the early 1980s coincides with a clear increase in mean air temperature and a marked reduction of relative humidity both annually and seasonally. This suggests that climate change processes driven by air temperature increase and relative humidity decrease affect the relationship between $\mathrm{E}_{\mathrm{Obs}}$ and $\mathrm{E}_{\mathrm{Est}}$.

\section{Discussion}

\subsection{Spatial relationship between average AED observations and estimations}


Spatially, the average annual and seasonal Piché and Pan evaporation rates show a clear latitudinal gradient from South (high values) to North (low values), with the exception of some observations located in the centre and the Northeast of the Iberian Peninsula, which correspond to semi-arid areas that also record high evaporation values. We found differences of 1961-2011 averaged Piché evaporation values of more than $1000 \mathrm{~mm}_{\text {year }}{ }^{-1}$ when comparing stations from the South and North. These differences were lower when considering Pan evaporation rates, but they also approached $1000 \mathrm{~mm}_{\text {year }}{ }^{-1}$. These marked latitudinal differences resemble the distribution of mean air temperature, cloudiness and relative humidity in Spain (Capel-Molina, 2000; Sanchez-Lorenzo et al., 2009; Vicente-Serrano et al., 2014a). The four physical models used to estimate evaporation (i.e. FAO-Penman-Monteith, FAO-Pan, PenPan and Penman) also showed this dominant South-North gradient, this spatially based difference was in order of $400 \mathrm{~mm} \mathrm{year}^{-1}, 600 \mathrm{~mm}$ year ${ }^{-1}, 900 \mathrm{~mm}$ year${ }^{1}$ to $600 \mathrm{~mm}$ year $^{-1}$, respectively, for the four models.

Different studies have shown strong agreement between monthly Pan observations and physical estimations by means of meteorological models; for instance, Hobbins et al. (2012) in USA, McMahon et al. (2013) in Australia, and Li et al. (2013) in northwest China revealed this behaviour using the PenPan model. Johnson and Sharma (2007) also showed strong agreement between Penman evaporation estimates and Pan evaporation observations in Australia. Also Jhajharia et al. (2009a) and Jahjharia et al. (2012) showed same decreasing trends in Pan evaporation observations and reference evapotranspiration in northeast India. We obtained correlation coefficients similar to these authors when relating monthly evaporation observations and estimates, with very few differences between the four models (Pearson's r coefficients varied between 0.81 and 0.83 for Piché evaporation and between 0.91 and 0.93 for Pan evaporation). In our study, the physical model that showed a better estimation with both Piché and Pan evaporation measurements was the FAO-Pan. The PenPan model shows some overestimation of monthly values, whereas the FAO-PenmanMonteith and Penman models tend to underestimate evaporation, mainly for the summer months 
with higher observed evaporation values. Nevertheless, published comparisons do not usually take into account evaporation seasonality and spatial differences when comparing evaporation observations and estimates. In Spain, the relationship between seasonal Piché and Pan average values and the four evaporation estimates is very strong. The spatial agreement between Piché evaporation and evaporation estimations is lower than that found between Pan evaporation and the four evaporation estimates, but these four models clearly overestimate evaporation in relation to Pan observations. Over this region climate conditions are highly variable in space, with strong latitudinal gradients in AED between the South and North (Vicente-Serrano et al., 2014b). Our spatial distribution of evaporation observations and estimates clearly identified these evaporation gradients.

\subsection{Temporal trends and relationships between $A E D$ observations $\left(E_{O b s}\right)$ and estimations $\left(E_{E s t}\right)$}

Although Pan evaporation has been the primary source of evaporation observations in several studies worldwide (e.g., Peterson et al., 1995; Roderick and Farquhar, 2002; McVicar et al., 2012a, 2012b), the Spanish time series are too short (i.e., 1984-2011) to allow a long-term assessment of AED trends. Availability of Piché measurements has allowed AED observations to be extended back to the 1960s with high confidence, given the strong relationship between Piché and Pan evaporation observations during the common period (1984-2011) (Sanchez-Loreno et al., 2014). Although there are some spatial differences in the correlation between annual and seasonal Piché and Pan evaporation observations, relationships are dominantly significant, mainly during spring, summer and autumn (correlation coefficients are higher than 0.78) when evaporation rates are relatively higher than winter rates. In addition, even though Piché evaporation observations have been used less frequently than Pan evaporation observations to assess AED variability and trends across the globe, here we showed their strong potential to complement the sub-optimal network of Spanish Pan evaporation observations (Stanhill, 2002; Fu et al., 2009), thus enabling an extension of the short time series in time and/or space. The simplicity and low uncertainty of Piché atmometer observations 
(where available) should reinforce its use in future studies on the AED and the hydrological cycle across the globe.

Temporal agreement between evaporation observations and estimates in Spain is very high. Correlation coefficients between Piché and Pan observations and the evaporation estimates by the four models are statistically significant, with the exception of the winter. The four methods provided practically the same results in terms of temporal variability and trends although the FAO-Pan equation shows better agreement with the monthly Piché and Pan observations across the wide range of Spanish climates.

There are no distinct spatial patterns in annual and seasonal correlation between evaporation observations and estimates. Regional Piché and Pan evaporation series show strong correlation with evaporation estimates, mainly for summer. This supports the use of evaporation estimates to determine AED variability and trends. This approach has been followed to determine changes in AED globally (e.g., Zhang et al., 2012). The advantage of using these models is that the control of all key meteorological forcings that govern AED rates, and that the possibility of quantifying the separate influence of the radiative and aerodynamic components is possible when using physically based models. In Spain, we showed that the AED estimated by means of the four methods shows a strong increase between 1961 and 2011, which oscillates between $22.7 \mathrm{~mm}_{\text {decade }}{ }^{-1}$ using the Penman model to $38.7 \mathrm{~mm}$ decade ${ }^{-1}$ using the PenPan model. The strong increase is statistically significant annually and seasonally. The magnitude of this increase agrees with AED trends estimated using simplified methods (based only on air temperature data; Vicente-Serrano et al., 2014b) and also with observations in other Mediterranean areas (Chaouche et al., 2010; Papaioaunou et al., 2011; Palumbo et al. 2011). Nevertheless, using EPiché observations we showed that trends in AED observations may diverge from estimations since the regional $E_{\text {Piché }}$ only shows an increase of 5.25 mm decade ${ }^{-1}$ over 1961-2011. 
The few studies that have compared variability of AED observations and estimates generally show a good temporal agreement regionally across the world (e.g., Chattopadhyay and Hulme, 1997; Xu et al., 2006; Li et al., 2013; You et al., 2013; Padmakumari et al., 2013), while other studies stressed divergences between $E_{O b s}$ and $E_{E s t}$ in some regions of the world. Wang et al. (2007) compared Pan evaporation and Penman-Monteith reference evapotranspiration trends in the Yangtze river basin (China), showing a greater decrease for Pan evaporation. Johnson and Sharma (2007) compared Pan evaporation and Penman evaporation trends across Australia and found that although having strong correlation between monthly evaporation observations and estimates, there were a weak relationship between the observed trends. These authors did not provide a conclusive response for this pattern but they suggested possible role of factors that determine the aerodynamic component.

In Spain we showed a similar pattern since although evaporation observations and estimates show strong correlation, we found that the general increase observed from evaporation estimates do not agree with observed Piché evaporation changes between 1961 and 2011. Annually, the increase in observations is not significant, and the magnitude of the significant increase observed in summer is much lower than that obtained from evaporation estimates. This is caused by a clear discontinuity in the relationship between the Piché evaporation observations and the evaporation estimates early in the 1980s; reasons for which are discussed below.

\subsection{Influence of climate variability on the AED evolution}

Different studies have suggested that solar radiation changes may be driving the Pan evaporation trends observed in different regions of the world (Stanhill and Cohen, 2001; Roderick and Farquhar, 2002; Xu et al., 2006). Here we showed high correlations between solar radiation and the Piché and Pan evaporation observations, both annually and seasonally (especially spring to autumn) across all stations. Thus, the regional annual and seasonal series of solar radiation closely resemble the series 
of Piché evaporation between 1961 and 2011. This suggests that available energy trends have played a major role to explain the evolution of Piché evaporation in Spain during the last decades. However, significant abrupt change in solar radiation early in the 1980s, that may explain different trends between evaporation observations and estimates, was identified.

Recent studies have stressed the important role of the aerodynamic component to explain evaporation trends in the last decades (Jhajharia et al., 2009b and 2014; Abtew et al., 2011; McVicar et al., 2012a, 2012b; Li et al., 2013; Padmakumari et al., 2013). As Johnson and Sharma (2007) suggested for Australia, the explanation of diverging trends found between evaporation observations and estimates is probably linked to the aerodynamic component of evaporation. Recent studies have hypothesized that wind speed may have an important role to explain evaporation changes globally (McVicar et al., 2012a, b). Nevertheless, in Spain recent increasing trends in reference evapotranspiration are mainly controlled by the decrease of relative humidity (Vicente-Serrano et al., 2014c) as a consequence of both air temperature increase and lower supply of moisture from the main terrestrial and oceanic moisture sources (Vicente-Serrano, 2014a). We showed strong negative correlation between relative humidity and Epiché. Although no a clear discontinuity between the annual and seasonal Piché evaporation series and the relative humidity series was found, there is a clear discontinuity in the relationship between air temperature and $E_{\text {Piché }}$ early in the 1980s, which is observed for the annual, winter, spring and autumn series. Therefore, although correlation between the evolution of $\mathrm{E}_{\mathrm{Obs}}$ and air temperature is lower than that found for other meteorological variables, the abrupt increase observed for air temperature could be in the root of the discontinuity found between $E_{O b s}$ and $E_{E s t}$ in Spain early in the 1980s. Air temperature shows a strong increase in Spain since the beginning of the twentieth century (Brunet et al., 2007), and the abrupt increase identified from the 1980s in the North hemisphere (Jones et al., 2012) is also detected in Spain. Moreover, another clue of the impact of air temperature on the discontinuity found between $\mathrm{E}_{\mathrm{Obs}}$ and $\mathrm{E}_{\mathrm{Est}}$, may be that the temporal discontinuity between air temperature and $E_{\text {Piché }}$ series is not significant in 
summer; the season which had the lowest discontinuity between $\mathrm{E}_{\mathrm{Obs}}$ and $\mathrm{E}_{\mathrm{Est}}$ early in the 1980s. This pattern, together with the $18.7 \mathrm{~mm}_{\text {decade }}{ }^{-1}$ precipitation decrease observed since the 1960s across Spain caused lower soil moisture availability and vapour supply to the atmosphere (VicenteSerrano et al., 2014c), resulted in a decrease of relative humidity, and probably indirectly affected the relationship between $\mathrm{E}_{\mathrm{Obs}}$ and $\mathrm{E}_{\mathrm{Est}}$.

Therefore, although some studies in different regions across the globe have reported a relatively small role of air temperature to explain current evaporation trends in comparison to other variables such as vapour pressure deficit, solar radiation and wind speed (e.g., Roderick and Farquhar, 2002; McVicar et al., 2012b, Table 7; Yang and Yang, 2012; Li et al., 2013), global warming could be indirectly affecting current evaporation processes: internal atmosphere feedbacks being challenging to resolve. This pattern could also amplify aridity because of the simultaneous decrease in precipitation observed in Spain (Vicente-Serrano et al., 2014a). Under strengthening aridity conditions, local advection effects may become relevant for evapotranspiration since they enhance evapotranspiration, particularly when the surrounding area is very dry (Brutsaert and Stricker, 1979). Further research is needed to determine physical mechanisms of the changes between $\mathrm{E}_{\mathrm{Obs}}$ and $\mathrm{E}_{\mathrm{Est}}$ using standard meteorological data and models that account for lateral flows of energy and moisture internal to Spain and from external land and ocean surfaces. Such research is highly relevant to enhance understanding of future water availability and ecosystems functioning in southern Europe under the current climate change scenario, given predictions of strong precipitation decreases and air temperature increases in coming decades (Giorgi and Lionello, 2008) culminating in an amplification of drought severity and aridity (Estrela et al., 2013).

\section{Conclusion}

To summarize, the main findings of this research conducted over Spain from 1961-2011 are: 
(i) Evaporation observations from Piché atmometers and Class-A Pan evaporimeters in 19 stations across Spain during a 28-yr period (1984-2011) showed a positive and statistically significant relationship, being much stronger in spring, summer and autumn.

(ii) Evaporation estimates by four physical models displayed positive and statistically significant correlations (except for winter months) with both Piché and Pan evaporation observations. Results showed that the FAO-Pan had the best agreement with observations, whereas the PenPan model tended to overestimate, and the FAO-Penman-Monteith and the Penman model to underestimate, observed evaporation rates.

(iii) Pan observations provided more coherent spatial agreement with modelled evaporation estimates when compared to those shown by Piché evaporation observations.

(iv) Long-term trends (i.e., 1961-2011) of evaporation rates estimated by the four physical models had a statistically significant increasing trend annually and seasonally. However, this increasing trend was not reflected in the Piché observations which displayed a discontinuity in the 1980s.

(v) Recent rapid increases in air temperature and the associated recent decline in relative humidity are the major driving factor explaining the abrupt discontinuity observed in the Piché evaporation observations as compared to the evaporation estimates across Spain during last few decades.

\section{Acknowledgements}

We would like to thank the Spanish State Meteorological Agency (AEMET) for providing the climate database used in this study. C. A-M was supported by the JCI-2011-10263 grant; and A. S-L received a postdoctoral fellowship from the "Secretaria per a Universitats i Recerca del Departament d’Economia i Coneixement, de la Generalitat de Catalunya i del programa Cofund de les Accions Marie Curie del 7è Programa marc d’R+D de la Unió Europea” (2011 BP-B 00078) and by the JCI- 
2012-12508 grant. This work was also supported by the research projects CGL2011-27574-CO2-02 financed by the Spanish Commission of Science and Technology and FEDER and "LIFE12 ENV/ES/000536-Demonstration and validation of innovative methodology for regional climate change adaptation in the Mediterranean area (LIFE MEDACC)” financed by the LIFE programme of the European Commission. The authors wish to acknowledge the editor and the two anonymous reviewers for their detailed and helpful comments to the original manuscript.

\section{References}

Abtew,W., Obeysekera, J., Iricanin, N., 2011. Pan evaporation and potential evapotranspiration trends in South Florida. Hydrol. Process. 25(6), 958-969.

Alexandersson H., 1986. A homogeneity test applied to precipitation data. J. Climatol. 6(6), 661675.

Allen, R.G., Pereira, L. S.,Raes, D., Smith, M., 1998. Crop evapotranspiration - Guidelines for computing crop water requirements - FAO Irrigation and drainage paper 56. Available at http://www.fao.org/docrep/x0490e/x0490e00.htm (last accessed 1 December 2014).

Austin, R.B., Cantero-Martínez, C., Arrúe, J.L., Playán, E., Cano-Marcellán, P., 1998. Yield-rainfall relationships in cereal cropping systems in the Ebro river valley of Spain. Eur. J. Agron. 8(34), 239-248.

Azorin-Molina, C., Vicente-Serrano, S.-M., McVicar, T. R., Jerez, S., Sanchez-Lorenzo, A., LópezMoreno, J.I., Revuelto, J., Trigo, R.M., Lopez-Bustins, J.A., Espírito-Santo, F., 2014.

Homogenization and assessment of observed near-surface wind speed trends over Spain and Portugal, 1961-2011. J. Clim. 27(10), 3692-3712. 
Bai, J., Perron, P., 2003. Computation and Analysis of Multiple Structural Change Models. J. Appl. Econom. 18(1), 1-22.

Brunet, M., Jones, P.D., Sigro, J., Saladie, O., Aguilar, E., Moberg, A., Della-Marta, P.M., Lister, D., Walther, A., López, D., 2007. Temporal and spatial temperature variability and change over Spain during 1850-2005. J. Geophys. Res. 112, D12117. doi:10.1029/2006JD008249.

Brutsaert, W., 2006. Indications of increasing land surface evaporation during the second half of the 20th century. Geophys. Res. Lett. 33(20), L20403. doi: 10.1029/2006GL027532.

Brutsaert, W., Stricker, H., 1979. An advection-aridity approach to estimate actual regional evapotranspiration. Water Resour. Res. 15(2), 443-450. doi: 10.1029/WR015i002p00443.

Capel-Molina, J.J., 2000. El clima de la península Ibérica. Ariel (colección Ariel Geografía), Barcelona. (In Spanish)

Carnicer, J., Coll, M., Ninyerola, M., Pons, X., Sánchez, G., Peñuelas, J., 2011. Widespread crown condition decline, food web disruption, and amplified tree mortality with increased climate change-type drought. P. Natl. Acad. Sci. USA 108(4), 1474-1478.

Chaouche, K., Neppel, L., Dieulin, C., Pujol, N., Ladouche, B., Martin, E., Salas, D., Caballero, Y., 2010. Analyses of precipitation, temperature and evapotranspiration in a French Mediterranean region in the context of climate change. Compt. Rendus Geosci. 342(3), 234 243.

Chattopadhyay, N., Hulme, M., 1997. Evaporation and potential evapotranspiration in India under conditions of recent and future climate change. Agr. Forest. Meteorol. 87(1), 55-73.

Cohen, S., Ianetz, A., Stanhill, G., 2002. Evaporative climate changes at Bet Dagan, Israel, 19641998. Agr. Forest. Meteorol. 111(2), 83-91.

Cong, Z.T., Yang, D.W., Ni, G.H., 2009. Does evaporation paradox exist in China?. Hydrol. Earth Syst. Sc. 13(1), 357-366. 
Donohue, R.J., McVicar, T.R., Roderick, M.L., 2010. Assessing the ability of potential evaporation formulations to capture the dynamics in evaporative demand within a changing climate. J. Hydrol. 386(1-4), 186-197.

Esteban-Parra, M.J., Rodrigo, F.S., Castro-Diez, Y., 1998. Spatial and temporal patterns of precipitation in Spain for the period 1880-1992. Int. J. Climatol. 18(14), 1557-1574.

Estrela, T., Pérez-Martin, M.A., Vargas, E., 2012. Impacts of climate change on water resources in Spain. Hydrolog. Sci. J. 57(6), 1154-1167.

Fu, G., Charles, S.P., Yu, J., 2009. A critical overview of pan evaporation trends over the last 50 years. Clim. Chang. 97(1), 193-214.

García-Ruiz, J.M., López-Moreno, J.I., Vicente-Serrano, S.M., Lasanta, T., Beguería, S., 2011. Mediterranean water resources in a global change scenario. Earth-Sci. Rev. 105(3-4), 121139.

Giorgi, F., Lionello, P., 2008. Climate change projections for the Mediterranean region. Glob. Planet. Change 63(2-3), 90-104.

Hidalgo, H.G., Cayan, D.R., Dettinger, M.D., 2005. Sources of variability of evapotranspiration in California. J. Hydrometeorol. 6 (1), 3-19.

Hobbins, M.T., Ramírez, J.A., Brown, T.C., 2004. Trends in pan evaporation and actual evapotranspiration across the conterminous U.S.: Paradoxical or complementary? Geophys. Res. Lett. 31(13), L13503. doi:10.1029/2004GL019846.

Hobbins, M., Wood, A., Streubel, D., Werner, K., 2012. What drives the variability of evaporative demand across the conterminous United States? . J. Hydrometeorol. 13(4), 1195-1214.

Jhajharia, D., Fancon, AK., Kithan, S.B., 2006. Correlation between pan evaporation and meteorological parameters under the climatic conditions of Jorhat (Assam). Journal of Indian Water Resources Society 26 (1-2), 39-42. 
Jhajharia, D., Shrivastava, S.K., Sarkar, D., Sarkar, S. 2009a. Temporal characteristics of pan evaporation trends under the humid conditions of northeast India. Agr.Forest Meteorol. 149 (5), 763-770.

Jhajharia, D., Agrawal, G.,Sevda, M.S. 2009b. Influence of meteorological parameters on pan evaporation at Agartala. Journal of Agricultural Engineering 46 (1), 23-26.

Jhajharia, D., Dinpashoh, Y., Kahya, E., Singh, V.P., Fakheri Fard, A. 2012. Trends in reference evapotranspiration in the humid region of northeast India. Hydrol. Process. 26 (3), 421-435.

Jhajharia, D., Kumar, R., Dabral, P.P., Singh, V.P., Choudhary, R.R., Dinpashoh, Y. 2014. Reference evapotranspiration under changing climate over the Thar Desert in India. Meteorol. Appl., DOI: $10.1002 /$ met.1471.

Johnson, F., Sharma, A., 2007. Estimating evaporation - Issues and challenges. MODSIM07 - Land, Water and Environmental Management: Integrated Systems for Sustainability, Proceedings, pp. 589-595

Johnson, F., Sharma, A., 2010. A comparison of Australian open water body evaporation trends for current and future climates estimated from class a evaporation pans and general circulation models. Journal of Hydrometeorology 11(1), 105-121.

Jones, P. D., Lister, D.H., Osborn, T.J., Harpham, C., Salmon, M., Morice, C.P., 2012. Hemispheric and large-scale land-surface air temperature variations: An extensive revision and an update to 2010. J. Geophys. Res. 117, D05127. doi:10.1029/2011JD017139.

Lanzante, J. R., 1996. Resistant, robust and non-parametric techniques for the analysis of climate data: theory and examples including applications to historical radiosonde station data. Int. J. Climatol. 16(11), 1197-1226.

Li, Z., Chen, Y., Shen, Y., Liu, Y.D., Zhang, S., 2013. Analysis of changing pan evaporation in the arid region of Northwest China. Water Resour. Res. 49(4), 2205-2212. 
Linacre, E.T., 1994. Estimating US Class A pan evaporation from few climate data. Water Int. 19 (1), 5-14.

Liu, X., Luo, Y., Zhang, D., Zhang, M., Liu, C., 2011). Recent changes in pan-evaporation dynamics in China. Geophys. Res. Lett. 38 (13), L13404. doi:10.1029/2011GL047929.

Liu, Q., McVicar, T.R., 2012. Assessing climate change induced modification of Penman potential evaporation and runoff sensitivity in a large water-limited basin. J. Hydrol. 464-465, 352-362.

Matsoukas, C., Benas, N., Hatzianastassiou, N., Pavlakis, K.G., Kanakidou, M., Vardavas, I., 2011. Potential evaporation trends over land between 1983-2008: Driven by radiative fluxes or vapour-pressure deficit?. Atmos. Chem. Phys. 11(1), 7601-7616.

McMahon, T.A., Peel, M.C., Lowe, L., Srikanthan, R., McVicar, T.R., 2013. Estimating actual, potential, reference crop and pan evaporation using standard meteorological data: A pragmatic synthesis. Hydrol. Earth Syst. Sci. 17(1), 1331-1363.

McVicar, T.R. et al., 2007. Spatially distributing monthly reference evapotranspiration and pan evaporation considering topographic influences. J. Hydrol. 338 (3-4), 196-220.

McVicar, T.R., Roderick, M.L., Donohue, R.J., Van Niel, T.G., 2012a. Less bluster ahead? ecohydrological implications of global trends of terrestrial near-surface wind speeds. Ecohydrology 5(4), 381-388.

McVicar, T.R., Roderick, M.L., Donohue, R.J., et al., 2012b. Global review and synthesis of trends in observed terrestrial near-surface wind speeds: Implications for evaporation. J. Hydrol. 416417, 182-205.

Monteith, J.L., 1965. Symposium Society Experimental Biology, 19, pp. 205-234. edited by: Fogg, G E Cambridge University Press, London.

Padmakumari, B., Jaswal, A.K., Goswami, B.N., 2013. Decrease in evaporation over the Indian monsoon region: Implication on regional hydrological cycle. Clim. Change 121(4), 787-799. 
Palumbo, A.D., Vitale, D., Campi, P., Mastrorilli, M., 2011. Time trend in reference evapotranspiration: analysis of a long series of agrometeorological measurements in Southern Italy. Irrig. Drain. Syst. 25(4), 395-411.

Papaioannou, G., Vouraki, K., Kerkides, P., 1996. Piche evaporimeter data as a substitute for Penman equation's aerodynamic term. Agr. Forest. Meteorol. 82(1-4), 83-92.

Papaioannou, G., Kitsara, G., Athanasatos, S., 2011. Impact of global dimming and brightening on reference evapotranspiration in Greece. J. Geophys. Res. D: Atmos. 116(D9), D09107. doi:10.1029/2010JD015525

Penman, H.L., 1948. Natural evaporation from open water, bare soil, and grass. Proc. Roy. Soc. London A193, 120-146.

Peterson, T.C., Golubev, V.S., Groisman, P.Y., 1995. Evaporation losing its strength. Nature 377, 687-688.

Roderick, M.L., Farquhar, G.D., 2002. The cause of decreased pan evaporation over the past 50 years. Science 298(5597), 1410-1411.

Roderick, M.L., Farquhar, G.D., 2004. Changes in Australian pan evaporation from 1970 to 2002. Int. J. Climatol. 24(9), 1077-1090.

Roderick, M.L., Rotstayn, L.D., Farquhar, G.D., Hobbins, M.T., 2007. On the attribution of changing pan evaporation. Geophys. Res. Lett. 34 (17), L17403. doi:10.1029/2007GL031166.

Roderick, M.L., Hobbins, M.T., Farquhar, G.D., 2009. Pan evaporation trends and the terrestrial water balance. I. Principles and observations. Geography Compass 3(2), 746-760.

Rotstayn, L.D., Roderick, M.L., Farquhar, G.D., 2006. A simple pan-evaporation model for analysis of climate simulations: Evaluation over Australia. Geophys. Res. Lett.33 (17), L17715. doi:10.1029/2006GL027114 
Sanchez-Lorenzo, A., Brunetti, M., Calbo, J., Martin-Vide, J., 2007. Recent spatial and temporal variability and trends of sunshine duration over the Iberian Peninsula from a homogenized dataset. J. Geophys. Res. - Atmos. 112 (D20), D20115. doi:10.1029/2007JD008677.

Sanchez-Lorenzo, A., Calbo, J., Brunetti, M., Deser, C., 2009. Dimming/brightening over the Iberian Peninsula: Trends in sunshine duration and cloud cover, and their relations with atmospheric circulation. J. Geophys. Res. - Atmos. 114, D00D09. doi:10.1029/2008JD011394.

Sanchez-Lorenzo, A., Calbó, J., Wild, M., 2012. Increasing cloud cover in the 20th century: Review and new findings in Spain. Clim. Past. 8, 1199-1212.

Sanchez-Lorenzo, A., Calbó, J., Wild, M., 2013. Global and diffuse solar radiation in Spain: building a homogeneous dataset and assessing their trends. Glob. Planet. Chang. 100, 343-352.

Sanchez-Lorenzo, A., Vicente-Serrano, S.M., Wild, M., Calbó, J., Azorin-Molina, C., Peñuelas, J., 2014. Evaporation trends in Spain. Feasibility and hidden potential of Piché evaporimeter as compared to pan observations. Clim. Res. 61, 269-280.

Shuttleworth, W.J. 1992. 'Chapter 4 Evaporation’ in Handbook of Hydrology edited by: Maidment D. R McGraw-Hill Inc., New York.

Sneyers, R., 1975. Sur l'Analyse Statistique des Series d'Observations, pp. 9-12. Tech. Note, 194, WMO, Geneva. (In French)

Stanhill, G., Cohen, S., 2001. Global dimming: a review of the evidence for a widespread and significant reduction in global radiation with discussion of its probable causes and possible agricultural consequences. Agric. For. Meteorol., 107(4), 255-278.

Stanhill, G., 2002. Is the class A evaporation pan still the most practical and accurate meteorological method for determining irrigation water requirements? Agric. For. Meteorol. 112(3-4), 233236.

Thom, A.S., Thony, J.-L., Vauclin, M., 1981. On the proper employment of evaporation pans and atmometers in estimating potential transpiration. Q. J. R. Meteorol. Soc. 107 (453), 711-736. 
Topalo

Agric. Environ. 10 (3-4), 960-962.

Vicente-Serrano, S.M., Aidel, Z., Lasanta, T., Pueyo, Y., 2012. Dryness is accelerating degradation of vulnerable shrublands in semiarid Mediterranean environments. Ecol. Monogr. 82(4), 407428.

Vicente-Serrano, S.M., Azorin-Molina, C., Sanchez-Lorenzo, A., Morán-Tejeda, E., LorenzoLacruz, J., Revuelto, J., López-Moreno, J.I., Espejo, F., 2014a. Temporal evolution of surface humidity in Spain: recent trends and possible physical mechanisms. Clim. Dyn. 42(9-10), 2655-2674.

Vicente-Serrano, S.M., Azorin-Molina, C., Sanchez-Lorenzo, A., Revuelto, J., López-Moreno, J.I., González-Hidalgo, J.C., Espejo, F., 2014b. Reference evapotranspiration variability and trends in Spain, 1961-2011. Glob. Planet. Change 121, 26-40.

Vicente-Serrano, S.M., Azorin-Molina, C., Sanchez-Lorenzo, A., Revuelto, J., López-Moreno, J.I., Espejo, F., 2014c. Sensitivity of reference evapotranspiration to changes in meteorological parameters in Spain (1961-2011). Water Resour. Res. doi:10.1002/2014WR015427.

Xu, C., Gong, L., Jiang, T., Chen, D., Singh, V.P., 2006. Analysis of spatial distribution and temporal trend of reference evapotranspiration and pan evaporation in Changjiang (Yangtze River) catchment. J. Hydrol. 327 (1-2), 81-93.

Yang, H., Yang, D., 2012. Climatic factors influencing changing pan evaporation across China from 1961 to 2001. J. Hydrol. 414-415, 184-193.

Yeşilirmak, E., 2013. Temporal changes of warm-season pan evaporation in a semi-arid basin in Western Turkey. Stoch. Environ. Res. Risk Assess. 27(2), 311-321.

Walter I.A., Allen, R.G., Elliot, R., Mecham, B., Jensen, M., Itenfisu, D., Howell, T.A., Snyder, R., Brown, P., Echings, S., Spofford, T., Hattendorf, M., Cuenca, R., Wright, J.L., Martin, D., 2000. ASCE standardized reference evapotranspiration equation, p 209-215. In Proceedings 
National Irrigation Symposium, Evans RG, Benham BL, Trooien TP (eds). ASAE: Phoenix, AZ, USA. Available at:

http://www.kimberly.uidaho.edu/water/asceewri/ascestzdetmain2005.pdf (last accessed 1 December 2014)

Wang, Y., Jiang, T., Bothe, O., Fraedrich, K., 2007. Changes of pan evaporation and reference evapotranspiration in the Yangtze River basin. Theor. Appl. Climatol. 90(1-2), 13-23.

Wang, K., Dickinson, R.E., Liang, S., 2012. Global Atmospheric Evaporative Demand over Land from 1973 to 2008. J. Climate 25(23), 8353-8361.

Willmott, C.J., 1982. Some comments on the evaluation of model performance. Bull Am Meteorol Soc 63(11), 1309-1313.

You, G. et al., 2013. On the attribution of changing pan evaporation in a nature reserve in SW China. Hydrol. Process. 27(18), 2676-2682.

Zhang, Y., Leuning, R., Chiew, F.H.S., et al., 2012. Decadal trends in evaporation from global energy and water balances. J. Hydrol. 13(1), 379-391. 
Table 1. Pearson's r values between the Spanish regional series of Piché (1961-2011) and Pan evaporation observations (1984-2011) and the regional series of evaporation estimates obtained by the four physical methods. Significant correlations at $p<0.05$ are bolded.

\begin{tabular}{|l|l|r|r|r|r|}
\hline & & FAO-PM & FAO-Pan & PenPan & Penman \\
\hline & Annual & $\mathbf{0 . 6 5}$ & $\mathbf{0 . 6 5}$ & $\mathbf{0 . 6 7}$ & $\mathbf{0 . 6 7}$ \\
\cline { 2 - 7 } & Winter & $\mathbf{0 . 5 1}$ & $\mathbf{0 . 4 4}$ & $\mathbf{0 . 5 7}$ & $\mathbf{0 . 5 3}$ \\
\cline { 2 - 7 } & Spring & $\mathbf{0 . 8 1}$ & $\mathbf{0 . 8 3}$ & $\mathbf{0 . 8 2}$ & $\mathbf{0 . 8 3}$ \\
\cline { 2 - 7 } & Summer & $\mathbf{0 . 8 8}$ & $\mathbf{0 . 8 8}$ & $\mathbf{0 . 8 9}$ & $\mathbf{0 . 8 9}$ \\
\cline { 2 - 7 } & Autumn & $\mathbf{0 . 8 1}$ & $\mathbf{0 . 8 1}$ & $\mathbf{0 . 8 2}$ & $\mathbf{0 . 8 3}$ \\
\hline & Annual & $\mathbf{0 . 5 7}$ & $\mathbf{0 . 6 0}$ & $\mathbf{0 . 5 8}$ & $\mathbf{0 . 5 9}$ \\
\cline { 2 - 7 } & Winter & -0.02 & 0.12 & 0.07 & 0.09 \\
\cline { 2 - 7 } & Spring & $\mathbf{0 . 6 9}$ & $\mathbf{0 . 7 1}$ & $\mathbf{0 . 6 8}$ & $\mathbf{0 . 6 8}$ \\
\cline { 2 - 7 } & Summer & $\mathbf{0 . 8 2}$ & $\mathbf{0 . 8 4}$ & $\mathbf{0 . 8 2}$ & $\mathbf{0 . 8 2}$ \\
\cline { 2 - 7 } & Autumn & $\mathbf{0 . 8 0}$ & $\mathbf{0 . 7 9}$ & $\mathbf{0 . 8 2}$ & $\mathbf{0 . 8 4}$ \\
\hline
\end{tabular}

Table 2. Annual and seasonal trends in the regional series of Piché observations and the four evaporation estimates. Magnitude is mm year decade ${ }^{-1}$ for the annual series, and mm season decade ${ }^{-1}$ for the seasonal series. Significant trends at $p<0.05$ are bolded.

\begin{tabular}{|c|c|c|c|c|c|}
\hline & Piché & FAO-PM & FAO-Pan & PenPan & Penman \\
\hline Annual & 5.25 & 22.90 & 32.40 & 38.68 & 22.67 \\
\hline Winter & -1.51 & 1.65 & 1.90 & 2.35 & 1.71 \\
\hline Spring & 0.17 & 7.01 & 9.34 & 10.99 & 6.76 \\
\hline Summer & 3.19 & 10.69 & 16.42 & 19.10 & 10.31 \\
\hline Autumn & -0.10 & 3.55 & 4.74 & 6.24 & 3.88 \\
\hline
\end{tabular}


$44,5^{\circ} \mathrm{N}, 3.95^{\circ} \mathrm{E}$

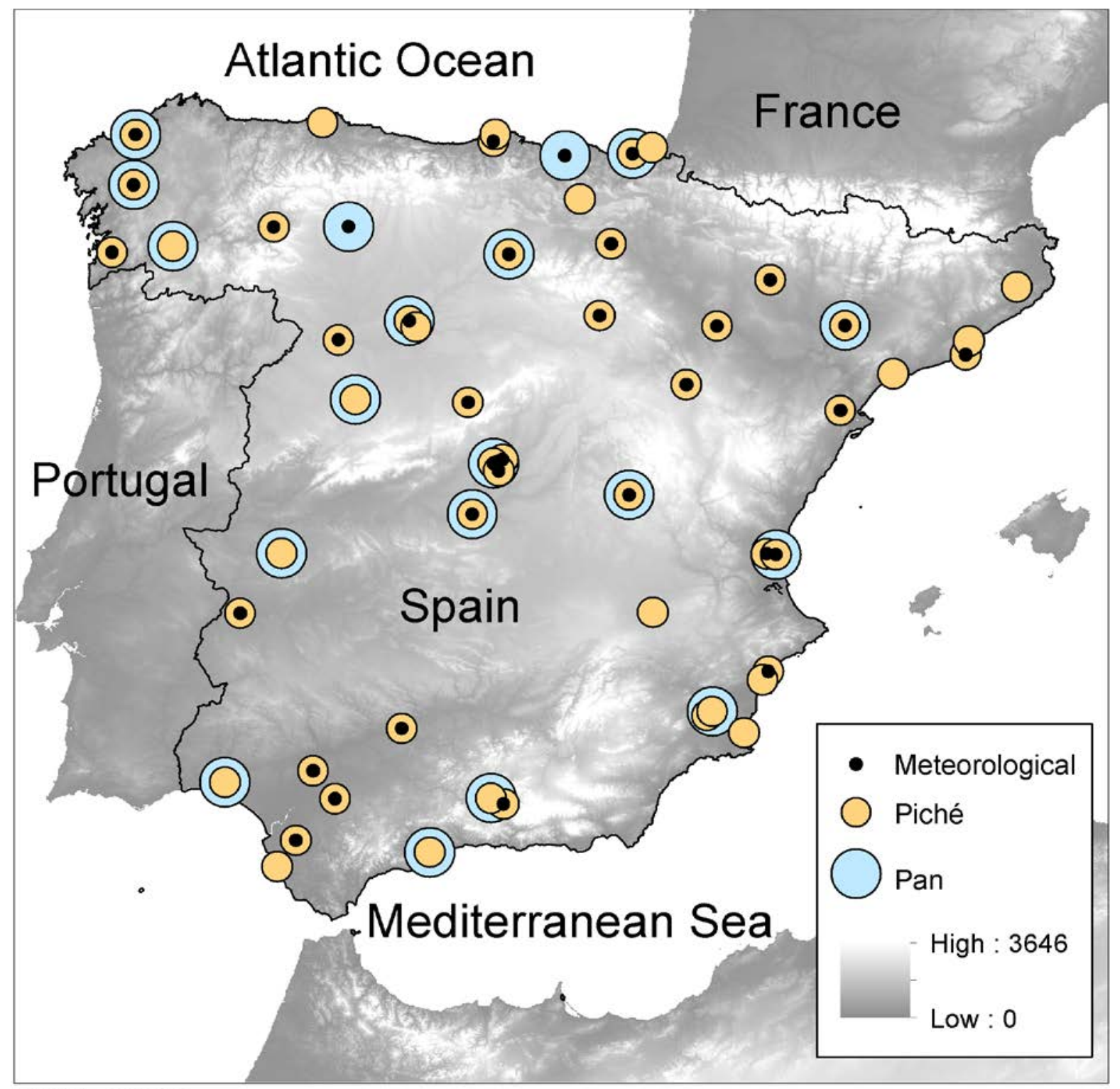

$34,5^{\circ} \mathrm{N}, 9.5^{\circ} \mathrm{W}$

Fig. 1. Spatial distribution of the stations used in this study. Cyan circles: Pan evaporation. Orange circles: Piché atmómeters. Black points: Series of meteorological variables. The grey-scale landsurface backdrop is a Digital Elevation Model and the units are m above mean sea level. 

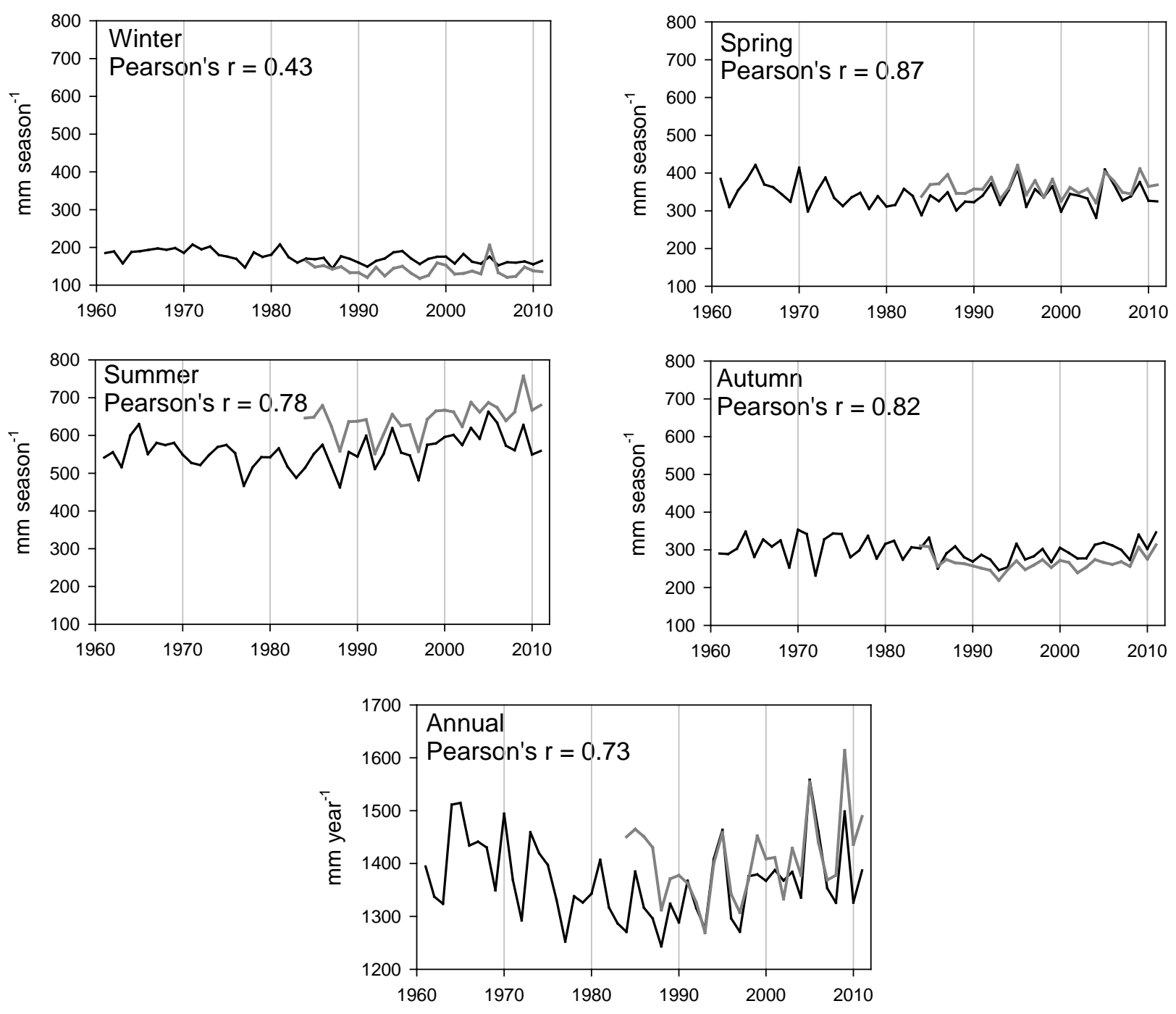

Fig. 2. Evolution of annual and seasonal averages from the 19 stations with available series of Piché (black solid line) and Pan (grey solid line) evaporation. Pearson's r coefficients are provided for the common period, 1984-2011. 


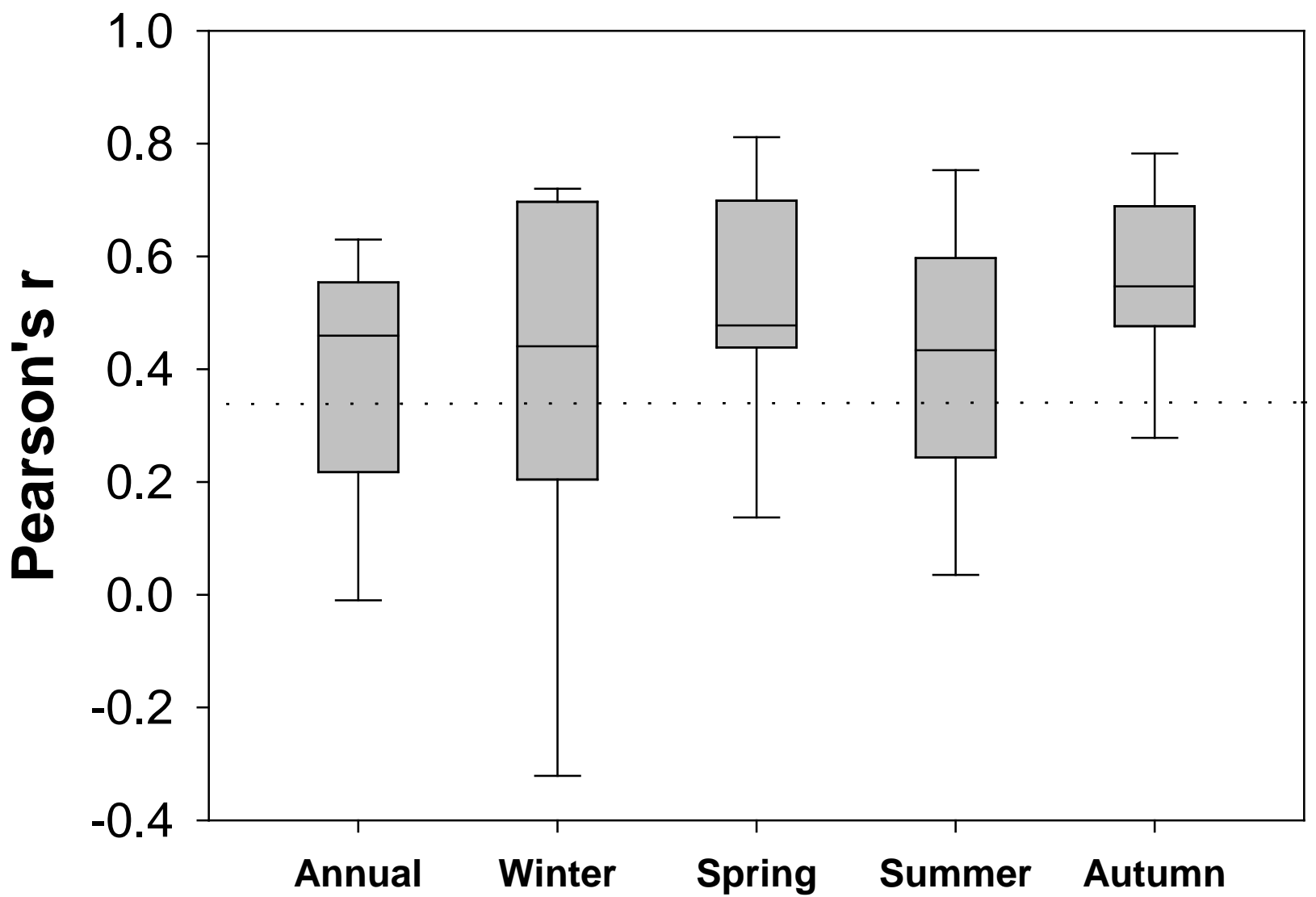

Fig. 3. Box-and-whisker plots of annual and seasonal Pearson's r correlations between Piché and Pan observed evaporation series for the 19 stations recording both variables from 1984-2011. Dashed line represents the threshold of significant correlations $(p<0.05)$. The mean (middle horizontal line) value, the $25^{\text {th }}$ and $75^{\text {th }}$ percentile range (boxes), and the $10^{\text {th }}$ and $90^{\text {th }}$ (whiskers) are represented. 
FAO-Penman Monteith
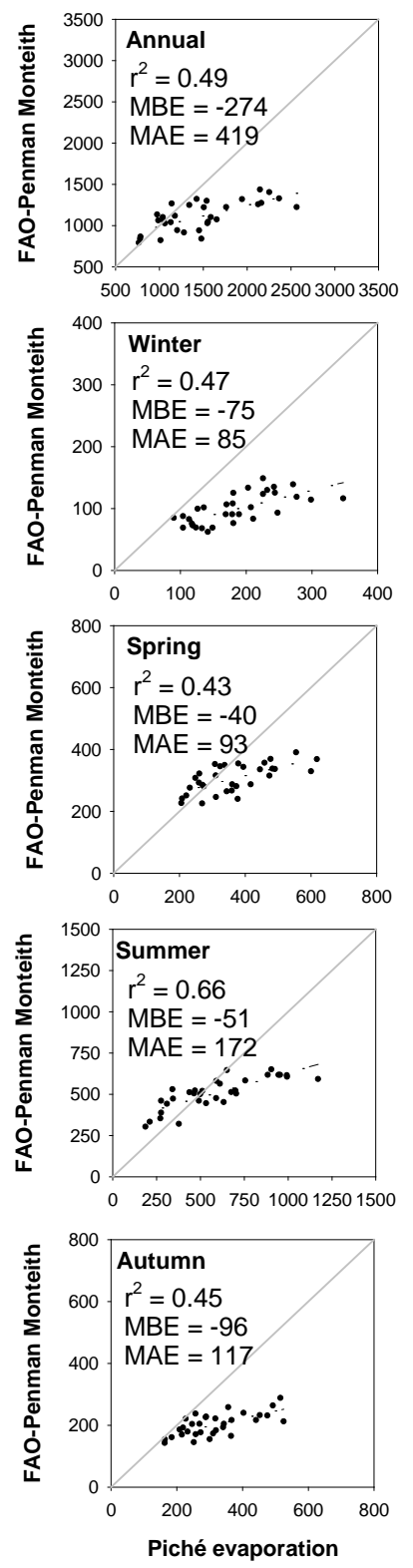

FAO-Pan
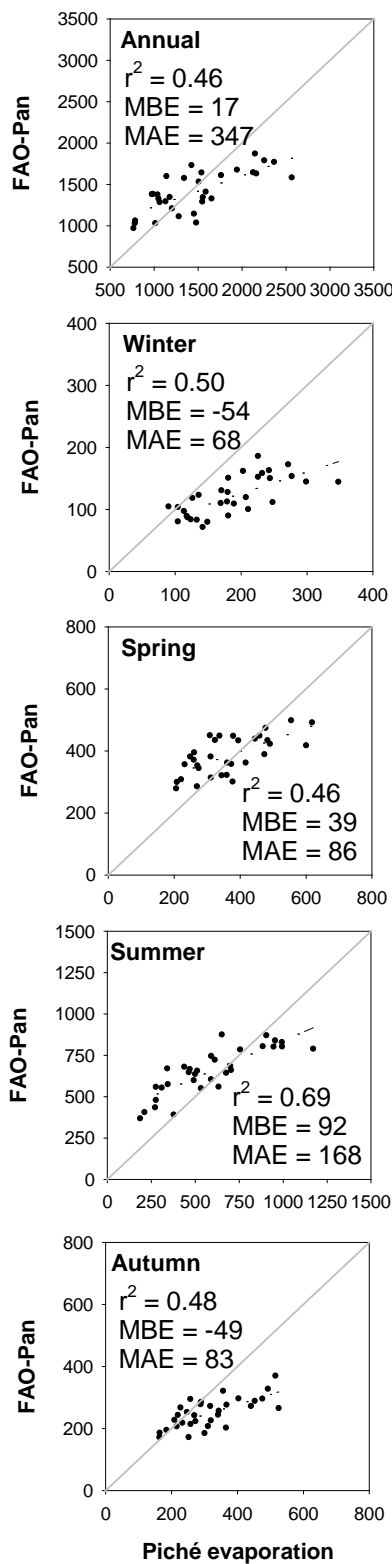

PenPan
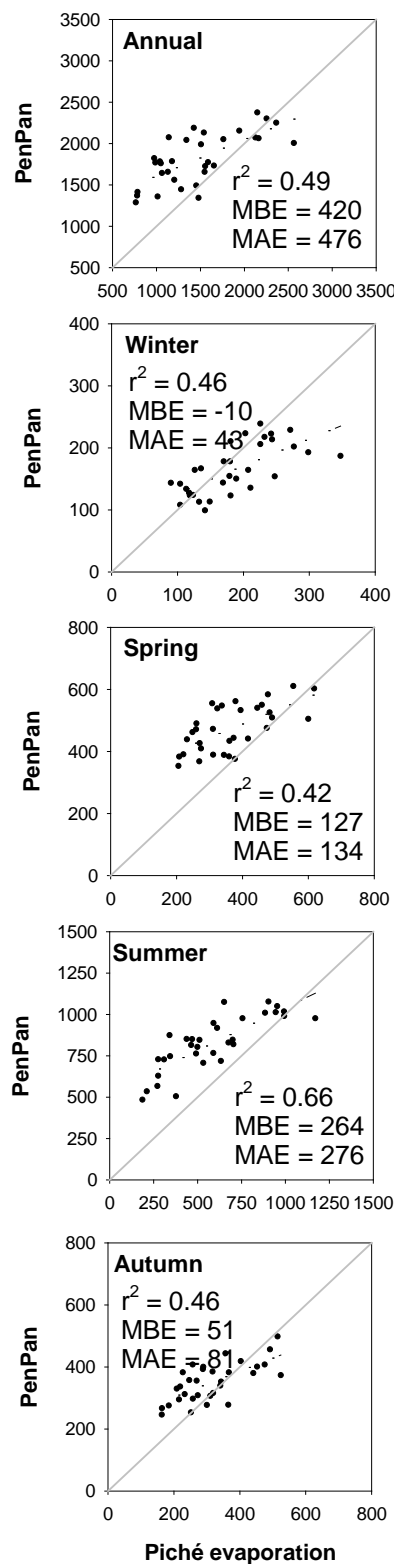

Penman
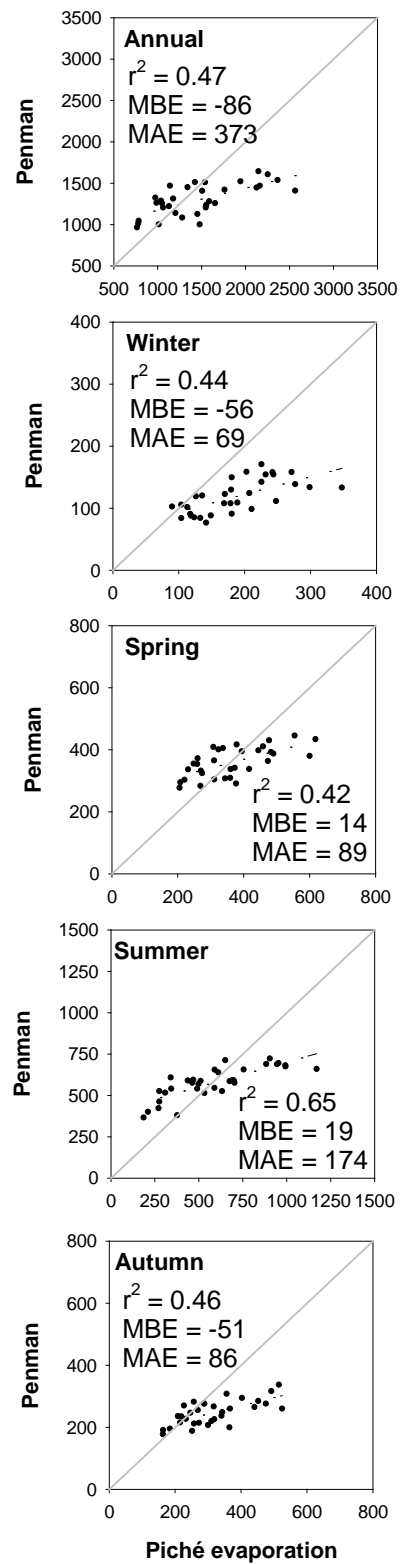

Fig. 4. Relationship between the annual and season integrated Piché evaporation observations (19612011) and the four evaporation estimates at 30 meteorological stations across Spain. For the annual plots the $\mathrm{X}$-axis and $\mathrm{Y}$-axis have units of $\mathrm{mm} / \mathrm{year}$, whereas for all seasonal plots both axes have units of $\mathrm{mm} / \mathrm{season}$. 
FAO-Penman Monteith
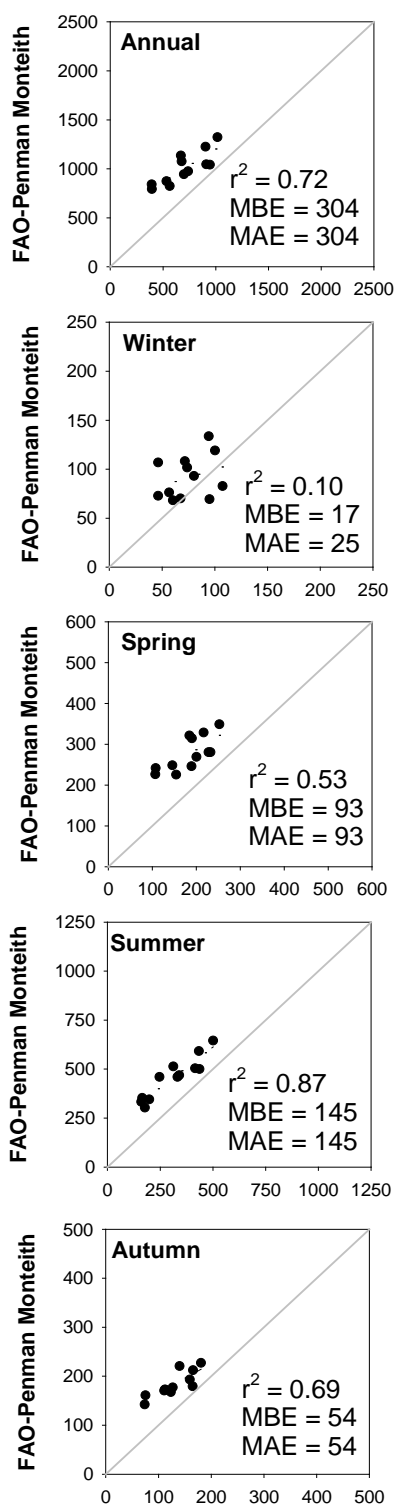

Pan evaporation
FAO-Pan
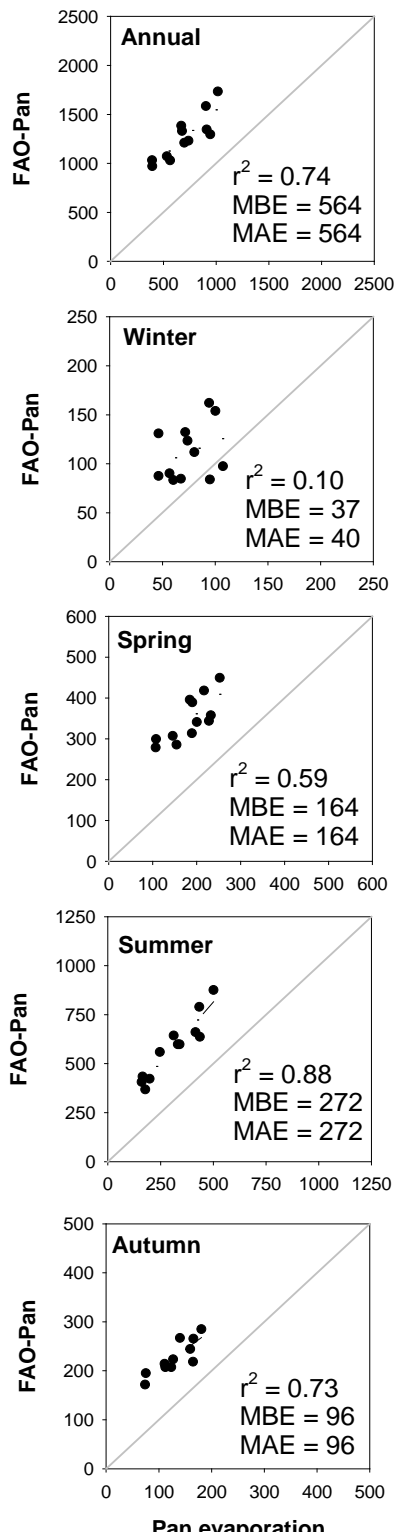

PenPan
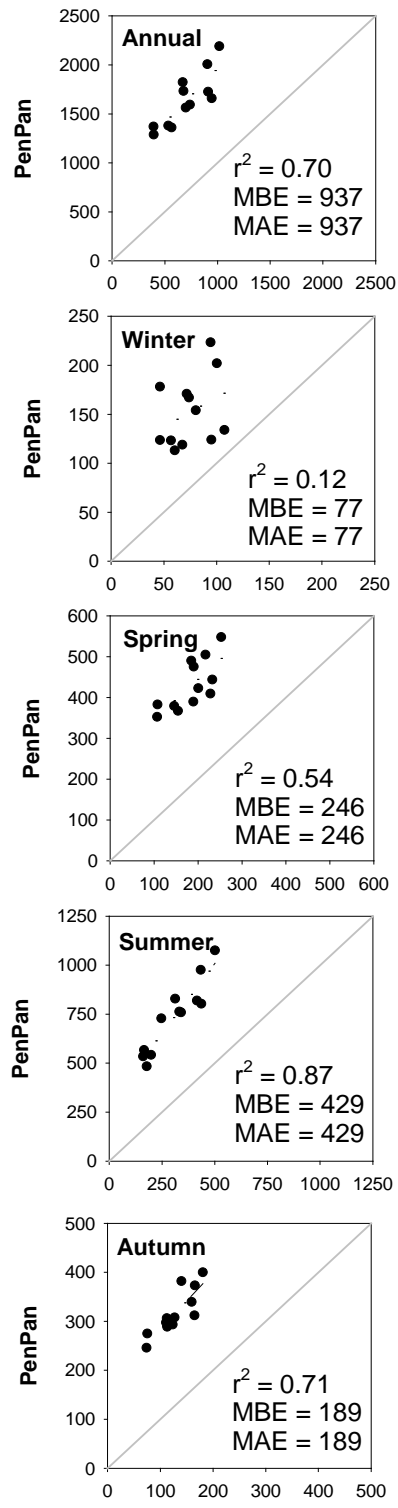

Pan evaporation
Penman
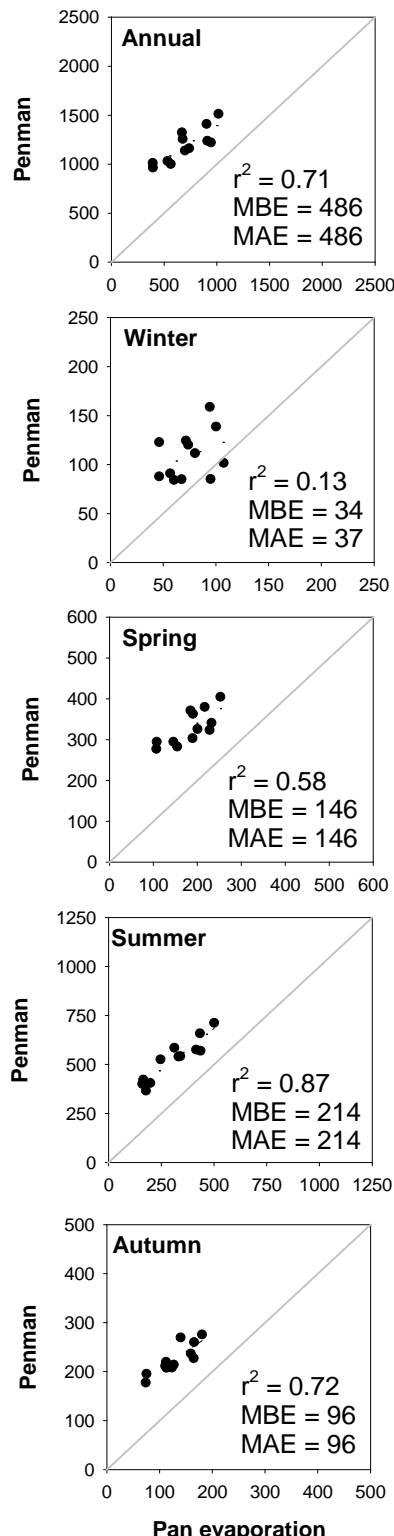

Fig. 5. Relationship between the annual and season integrated Pan evaporation observations (19842011) and the four evaporation estimates at 12 meteorological stations across Spain. For the annual plots the $\mathrm{X}$-axis and $\mathrm{Y}$-axis have units of $\mathrm{mm} /$ year, whereas for all seasonal plots both axes have units of $\mathrm{mm} / \mathrm{season}$. 

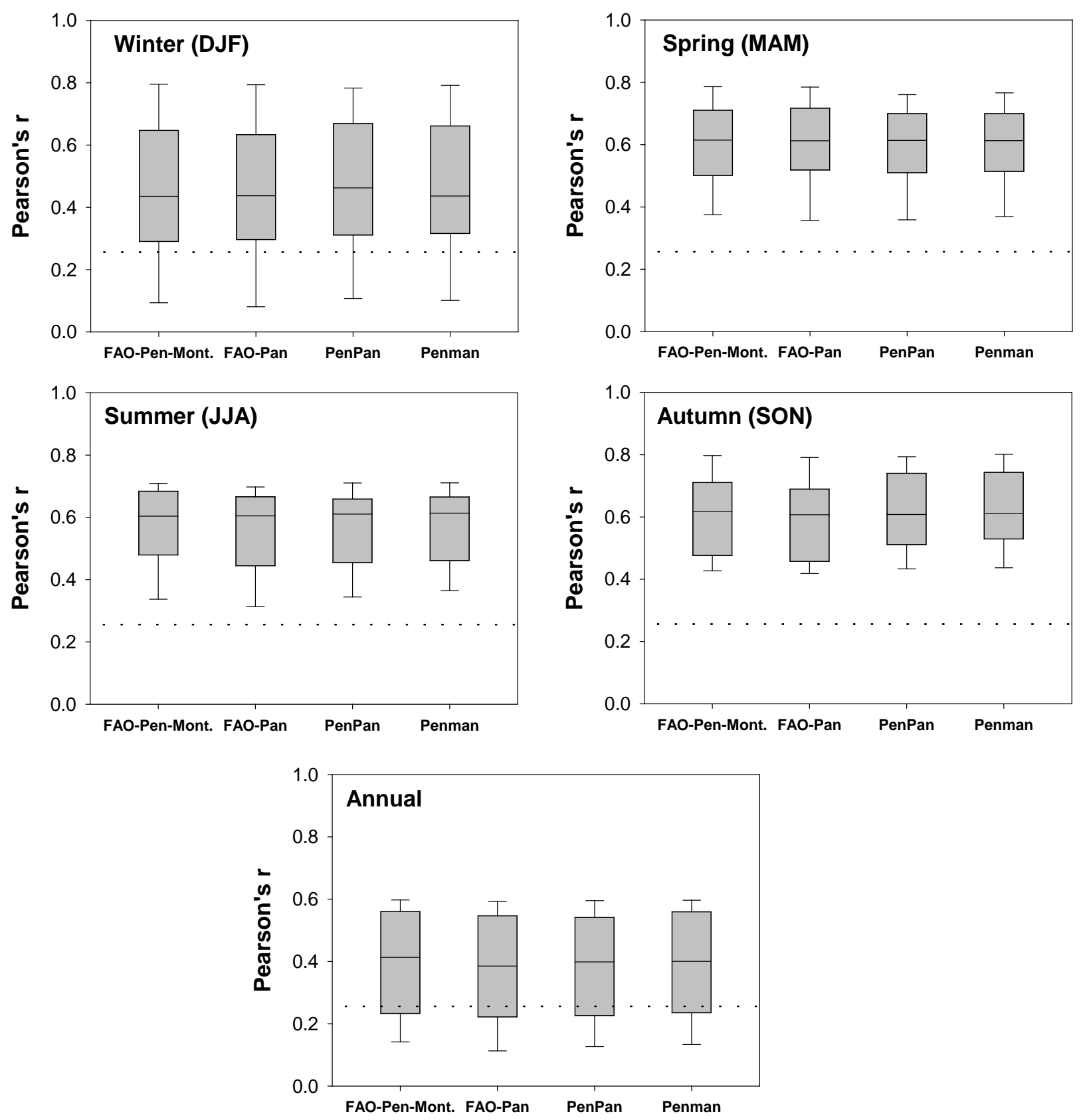

Fig. 6. Box-and-whisker plots with the annual and seasonal Pearson's r correlations between Piché evaporation observations and evaporation estimates using the four different methods at 30 meteorological stations (1961-2011). Dashed line represents the threshold of significant correlations $(p<0.05)$. The mean (middle horizontal line) value, the $25^{\text {th }}$ and $75^{\text {th }}$ percentile range (boxes), and the $10^{\text {th }}$ and $90^{\text {th }}$ (whiskers) are represented. 

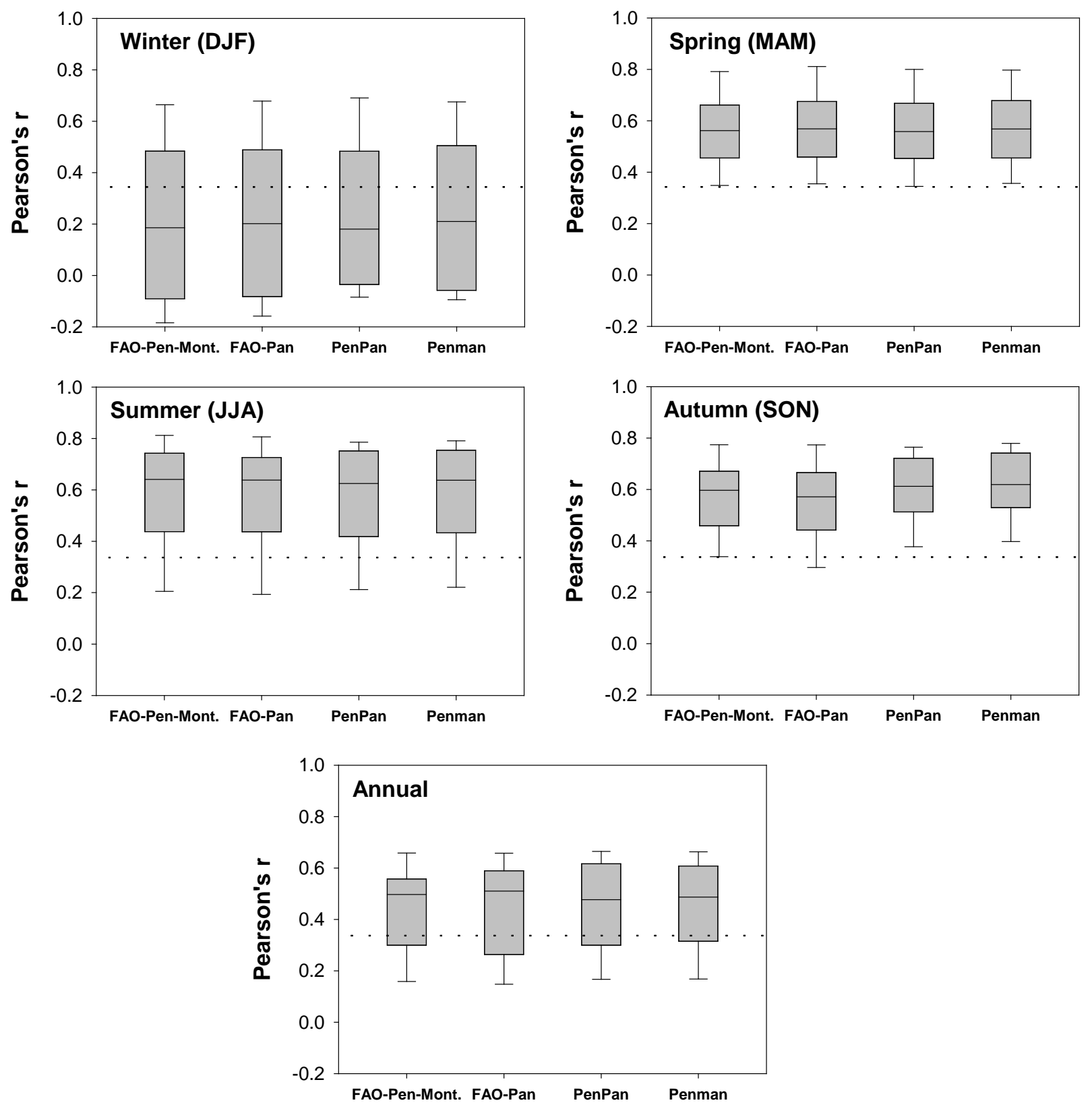

Fig. 7. Box-and-whisker plots with the annual and seasonal Pearson's r correlations between Pan evaporation observations and evaporation estimates using the four different methods at 12 meteorological stations (1984-2011). Dashed line represents the threshold of significant correlations $(p<0.05)$. The mean (middle horizontal line) value, the $25^{\text {th }}$ and $75^{\text {th }}$ percentile range (boxes), and the $10^{\text {th }}$ and $90^{\text {th }}$ (whiskers) are represented. 

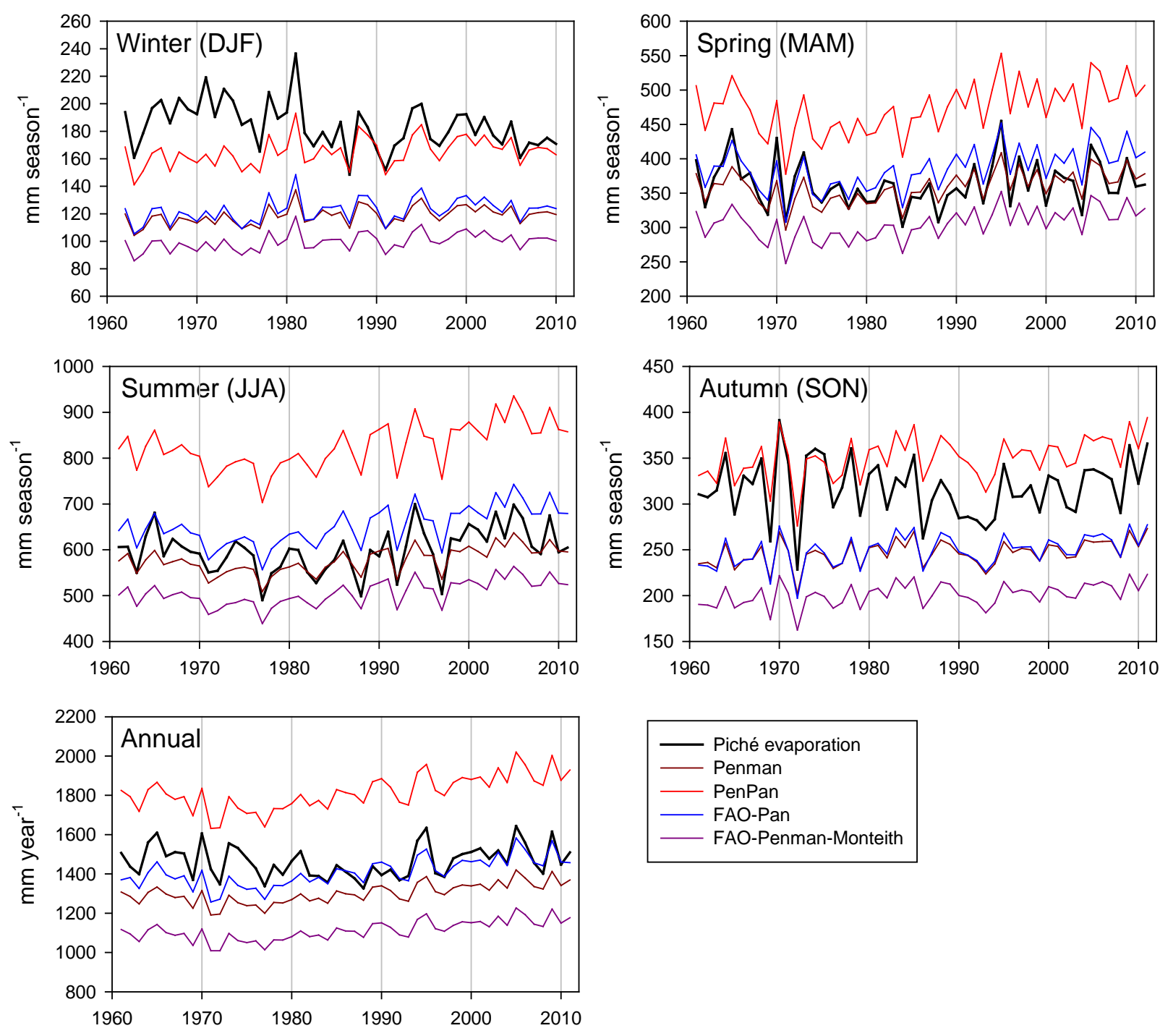

Fig. 8. Temporal evolution of the Spanish annually and seasonally integrated Piché evaporation observations and evaporation estimates by the four methods. The annual and seasonal trends for each evaporation time series are reported in Table 2. 

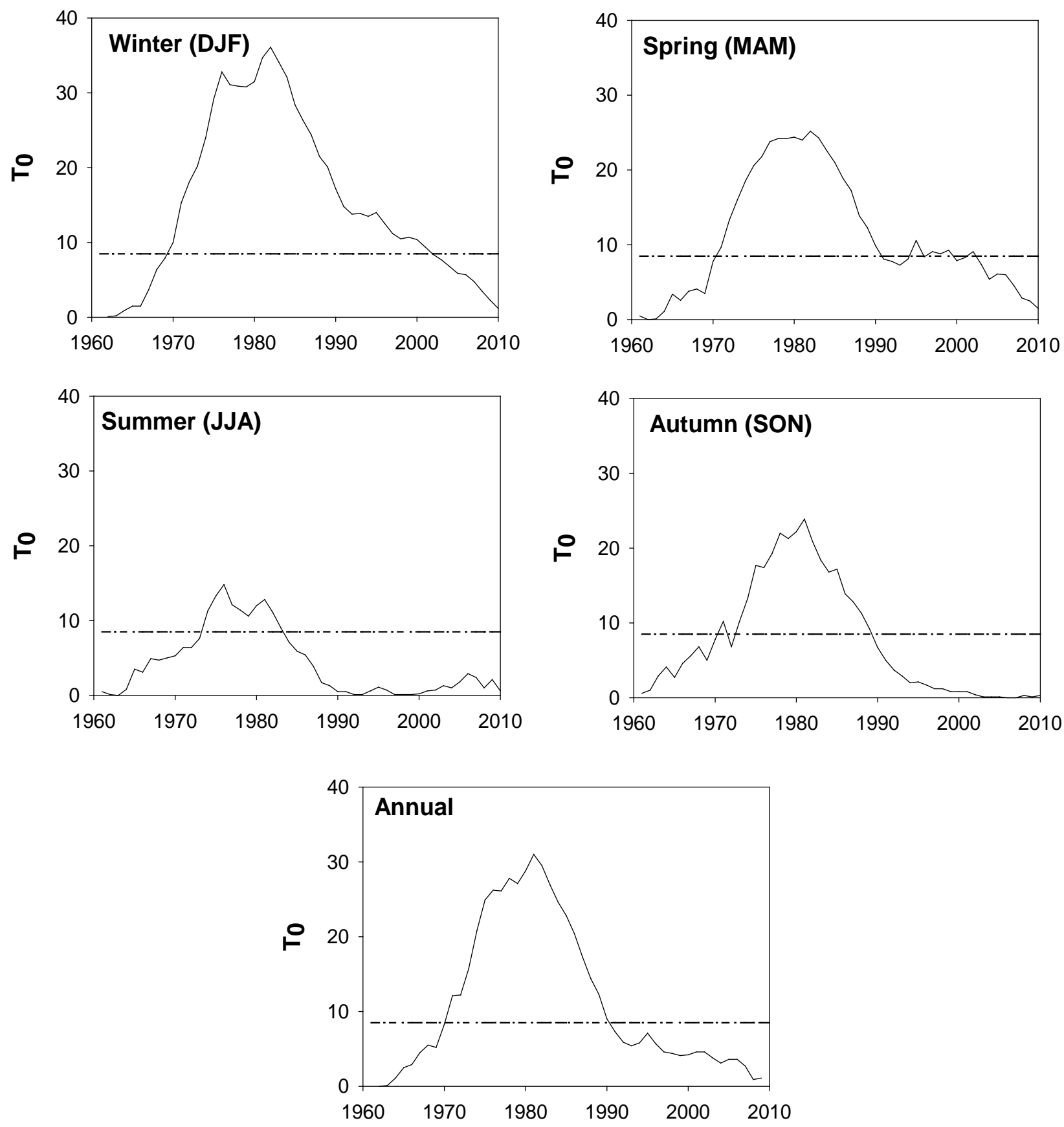

Fig. 9. Evolution of the SNHT statistic, $\mathrm{T}_{0}$, for the annual and seasonal regional series of observed Piché evaporation considering the FAO-Pan estimate of regional series as reference. Dashed line indicates the signification threshold $(\mathrm{p}<0.05)$. 

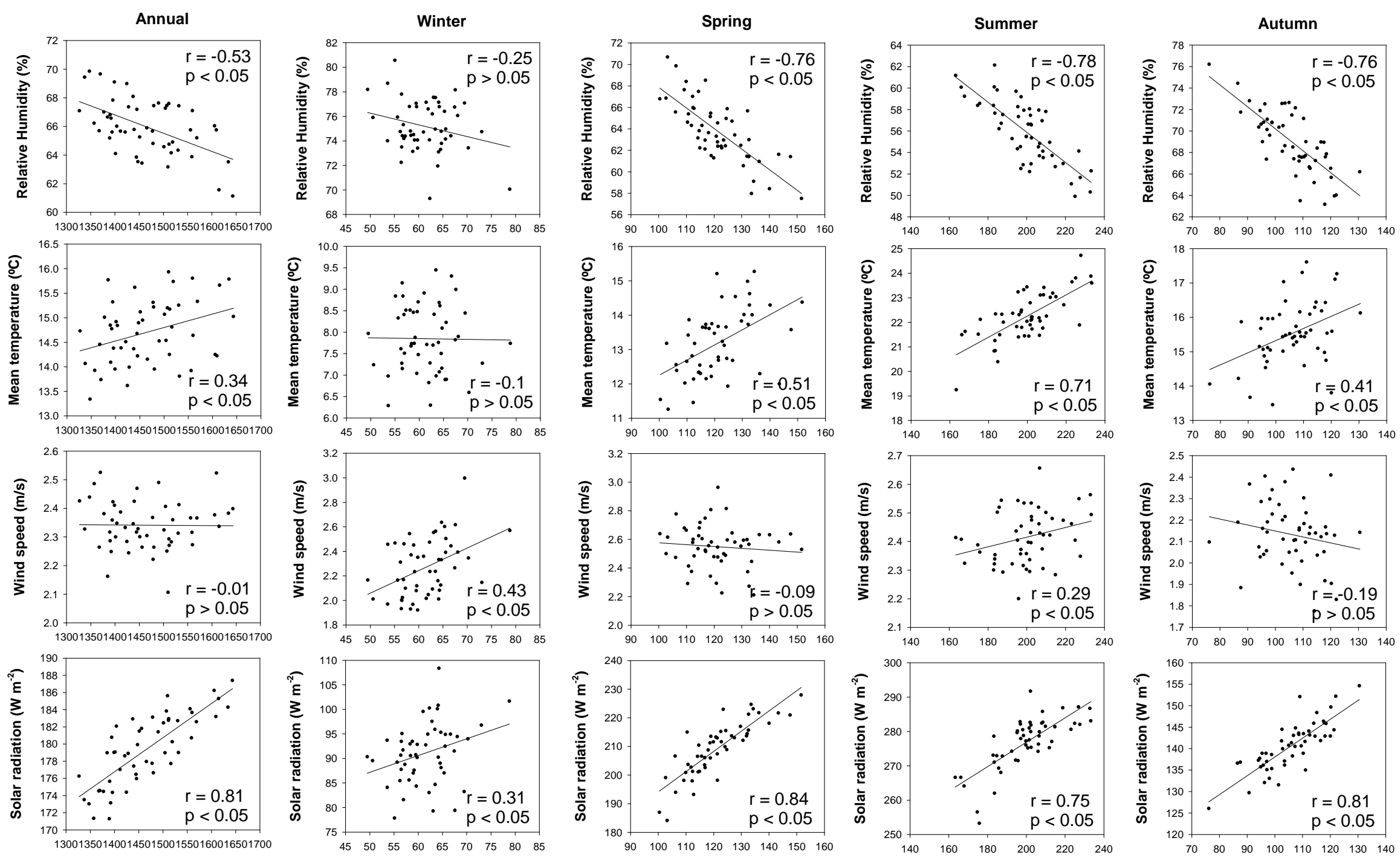

Piché evaporation

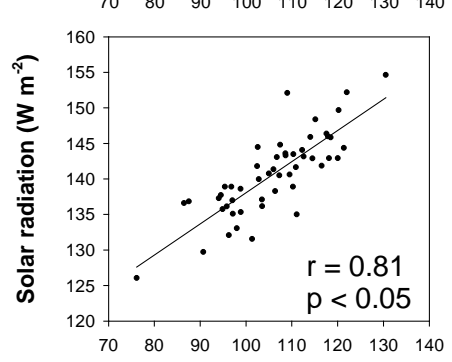

Piché evaporation

Piché evaporation

Fig. 10. Relationship between temporal variability of annual and seasonal regional Piché evaporation observations and regional series of relative humidity, mean air temperature, wind speed and solar radiation at the 56 stations for 1961-2011. 

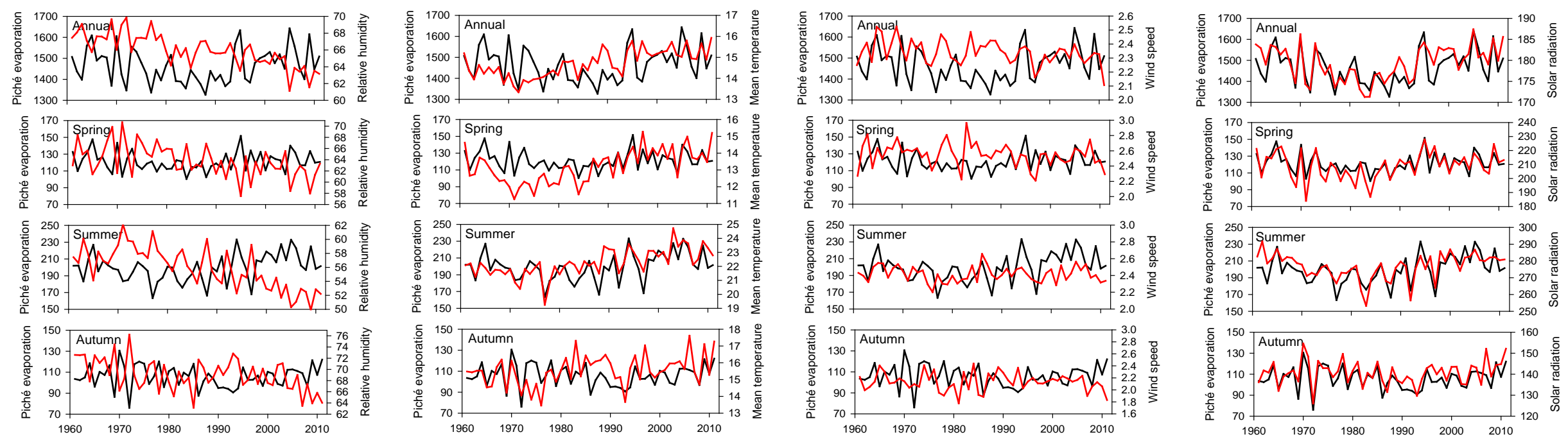

Fig. 11. Temporal evolution of annual and seasonal (winter is not shown) regional Piché evaporation (in mm, black line) and regional relative humidity (in \%), mean air temperature (in ${ }^{\circ} \mathrm{C}$ ), wind speed (in $\mathrm{m} \mathrm{s}^{-1}$ ) and solar radiation (in $\mathrm{W} \mathrm{m}^{-2}$ ) for 1961-2011. 
Relative humidity

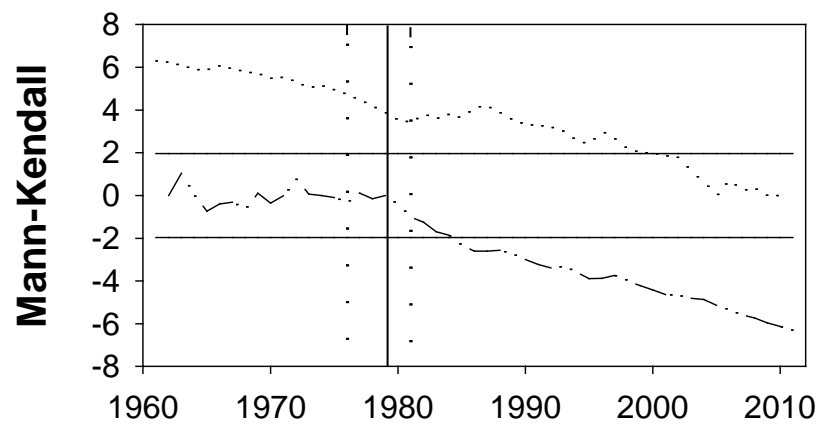

Wind speed

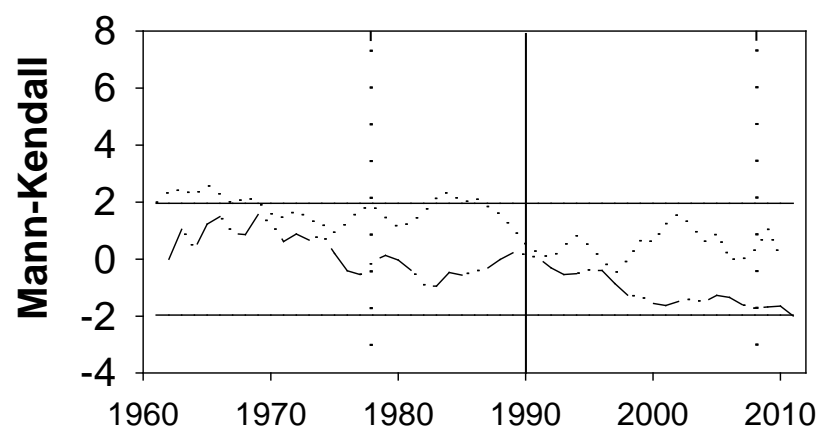

Mean air temperature

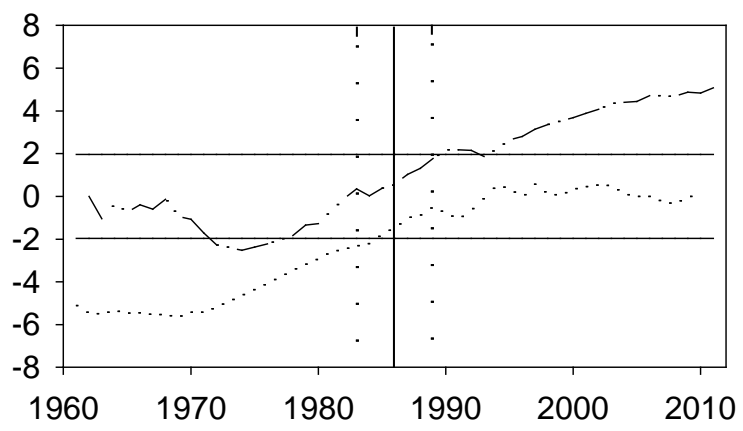

Solar radiation

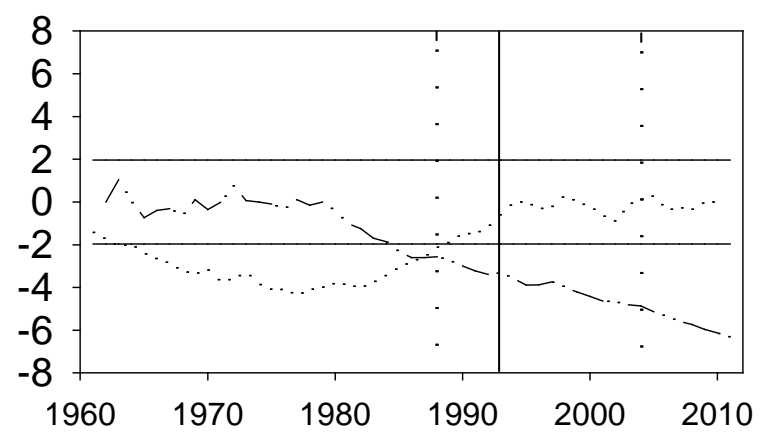

Fig. 12. Sequential version of Mann-Kendall test (C1 solid line; C2 dotted line). Horizontal solid lines represent the $5 \%$ significance level. The vertical solid line indicates the most probable break in the series according to the Bai \& Perron test. Dashed vertical lines indicate the confidence intervals for the break points. 

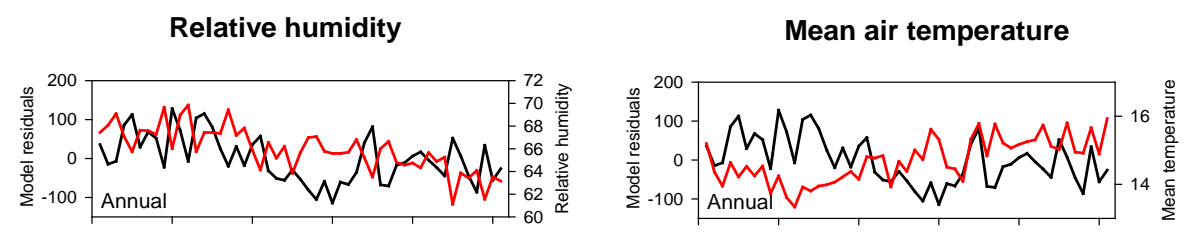

(1)

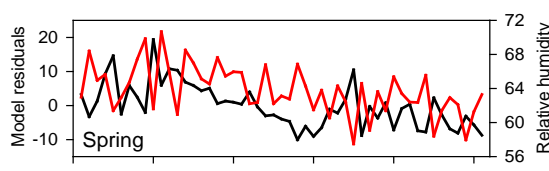

竞

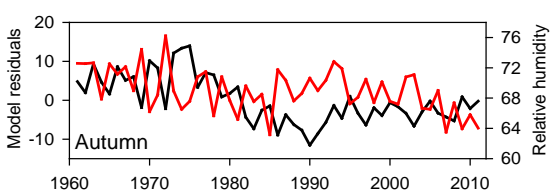

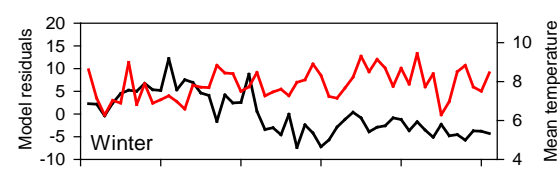
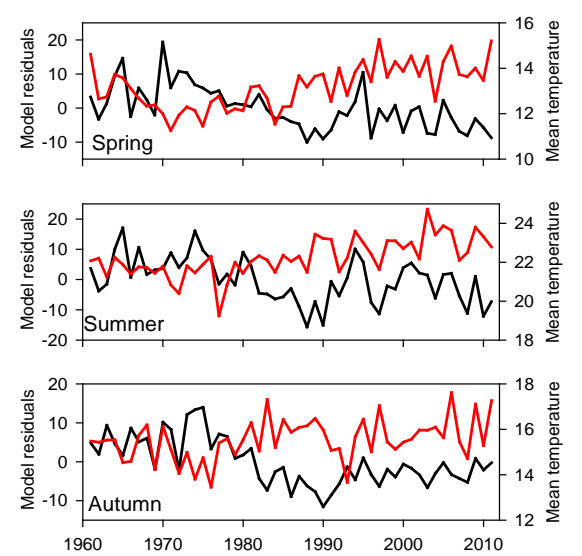
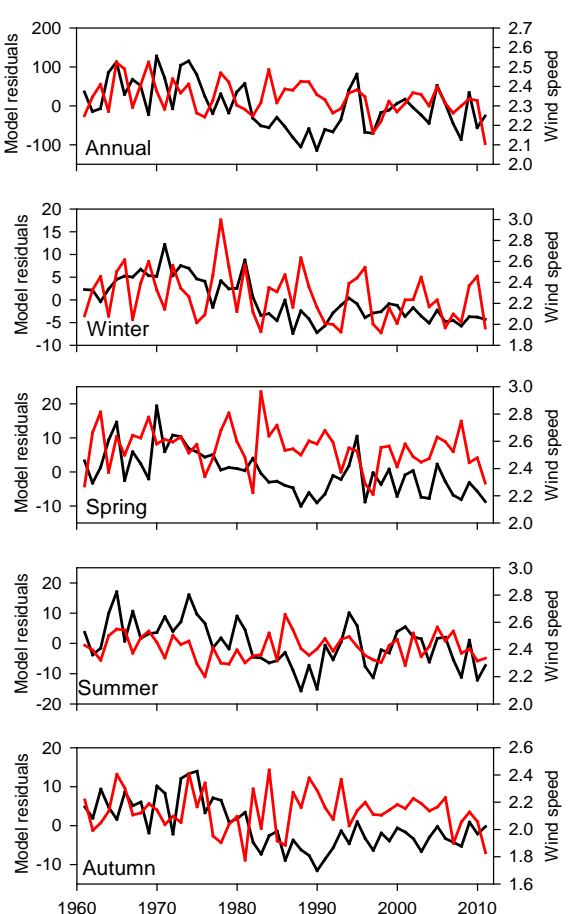

Solar radiation
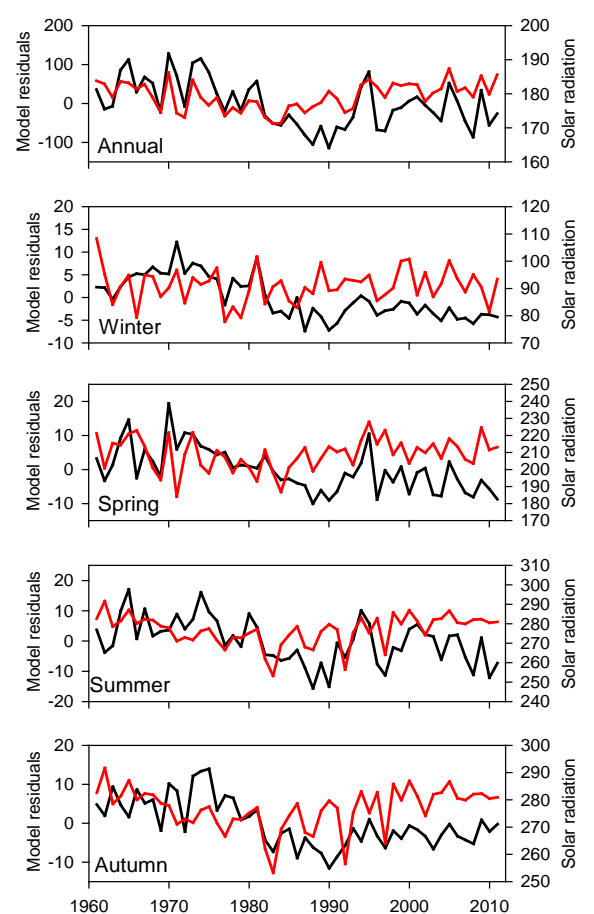

Fig. 13. Evolution of annual and seasonal residuals of the PenPan-Piché evaporation regression model and the evolution of relative humidity, solar radiation and mean air temperature across Spain during 1961-2011 
Supplementary Figures and Table:

\section{Atmospheric evaporative demand observations, estimates and driving factors in Spain (1961-2011)}

\begin{tabular}{|l|r|r|r|r|}
\hline & $\begin{array}{c}\text { Relative } \\
\text { Humidity }\end{array}$ & $\begin{array}{c}\text { Mean air } \\
\text { temperature }\end{array}$ & $\begin{array}{c}\text { Wind } \\
\text { speed }\end{array}$ & $\begin{array}{c}\text { Solar } \\
\text { radiation }\end{array}$ \\
\hline Annual & $\mathbf{- 0 . 7 9}$ & $\mathbf{0 . 5 9}$ & -0.03 & $\mathbf{0 . 7 6}$ \\
\hline Winter & $\mathbf{- 0 . 5 4}$ & 0.27 & $\mathbf{0 . 4 2}$ & $\mathbf{0 . 4 3}$ \\
\hline Spring & $-\mathbf{0 . 9 1}$ & $\mathbf{0 . 7 0}$ & -0.01 & $\mathbf{0 . 8 5}$ \\
\hline Summer & $\mathbf{- 0 . 8 8}$ & $\mathbf{0 . 8 1}$ & 0.21 & $\mathbf{0 . 7 9}$ \\
\hline Autumn & $-\mathbf{0 . 8 6}$ & $\mathbf{0 . 5 8}$ & -0.22 & $\mathbf{0 . 6 6}$ \\
\hline
\end{tabular}

Supplementary Table 1. Pearson's r values between the Spanish regional series of Piché (19612011) and the regional series of relative humidity, mean air temperature, wind speed and solar radiation. Bold types represent significance level of $p<0.05$. 

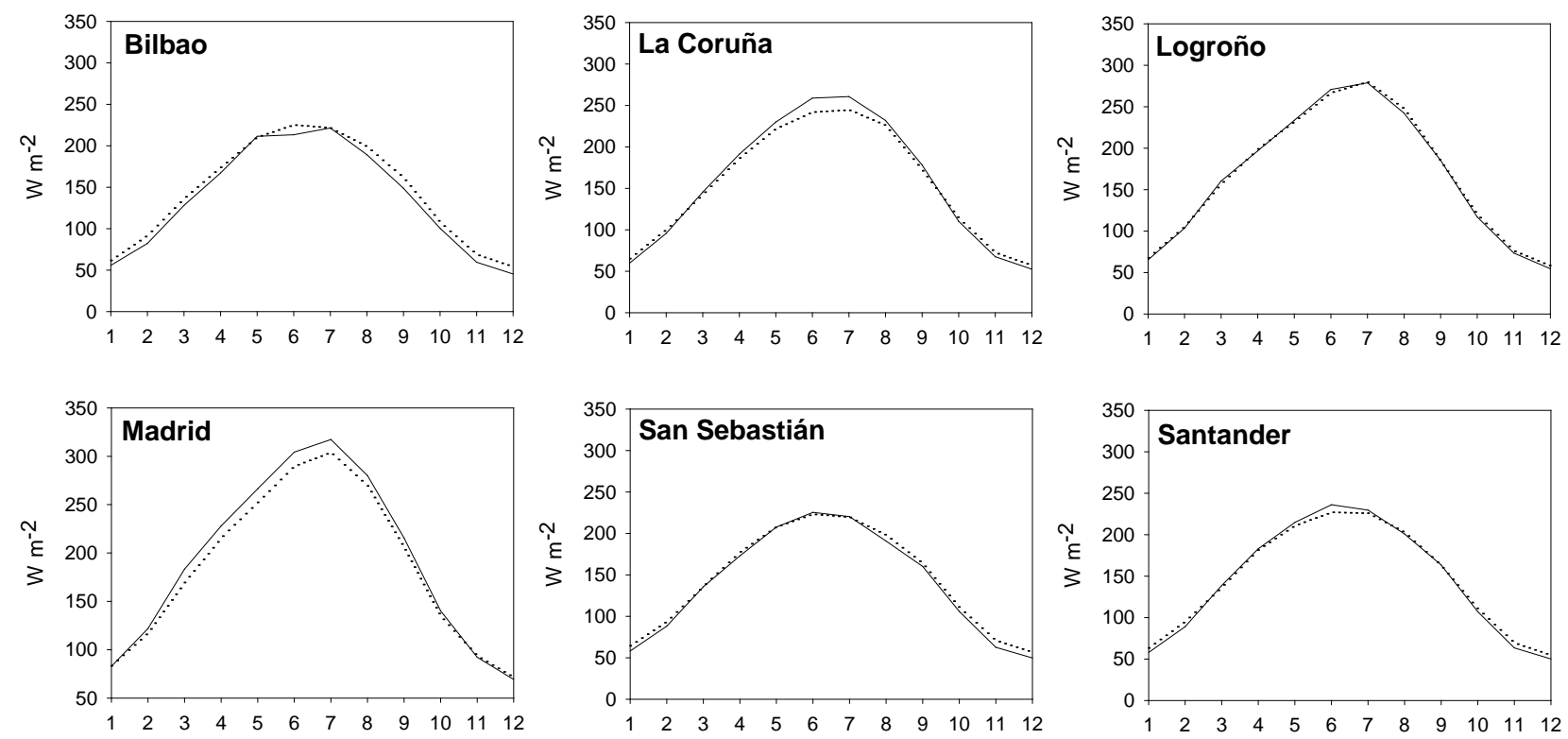

Supplementary Fig. 1. Mean monthly values of observed incoming solar radiation (Rs, solid line) and those estimated by equation 35 (dashed line) in Allen et al. (1998) at 6 meteorological stations in Spain (1984-2011). 

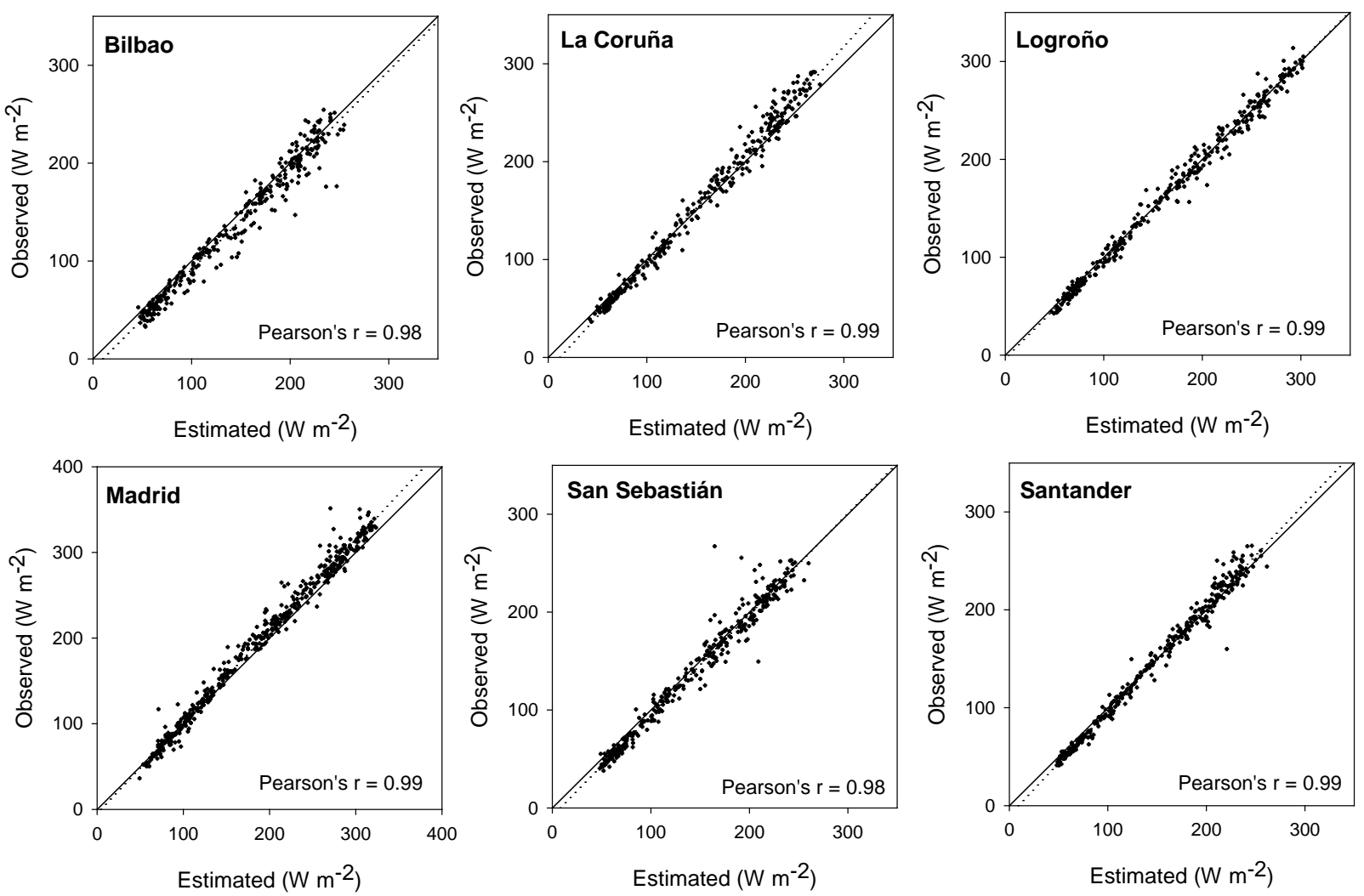

Supplementary Fig. 2. Relationship between monthly incoming Rs observations and Rs estimates at 6 meteorological stations in Spain (1984-2011). 

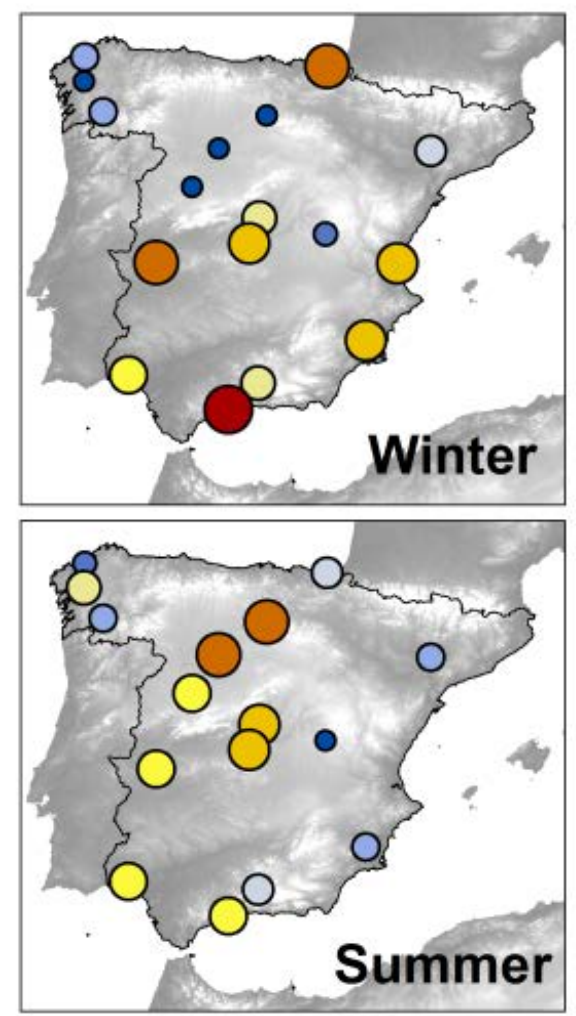
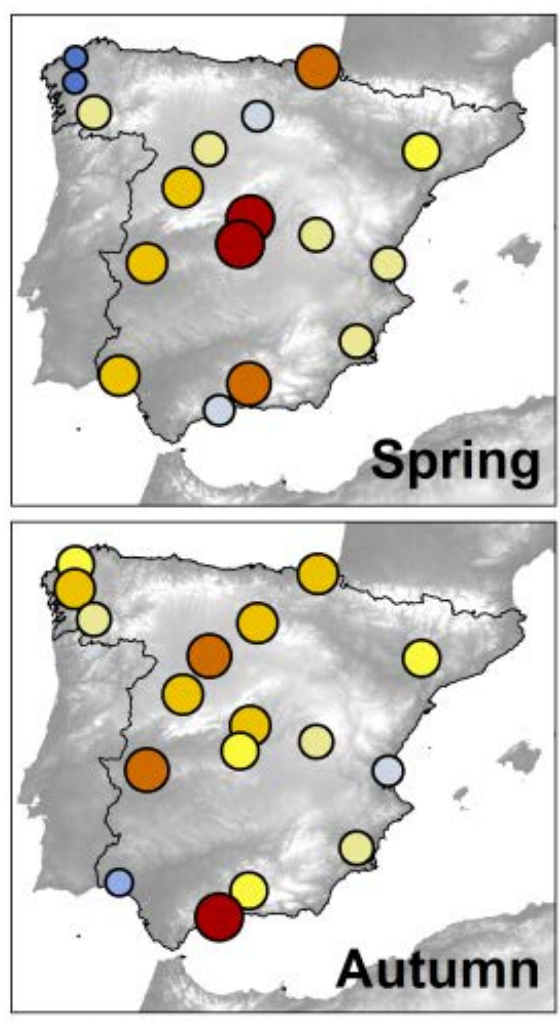

- $\quad<0.1$

○ $\quad 0.1-0.2$

○ $\quad 0.2-0.3$

O $\quad 0.3-0.4$

○ $\quad 0.4-0.5$

$\bigcirc \quad 0.5-0.6$

O $0.6-0.7$

$0.7-0.8$

$>0.8$

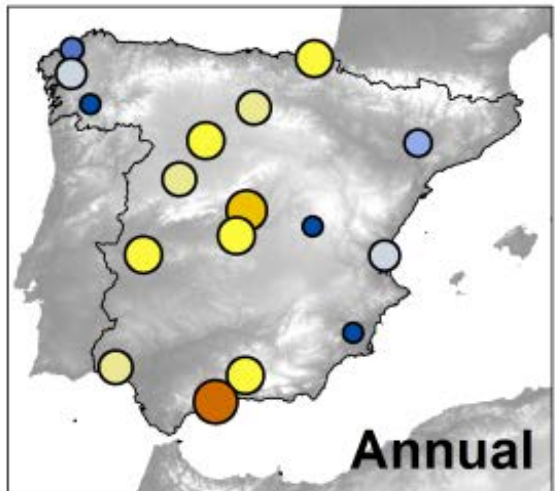

Supplementary Fig. 3. Spatial distribution of annual and seasonal correlation between observed Pan and observed Piché series (1984-2011) 

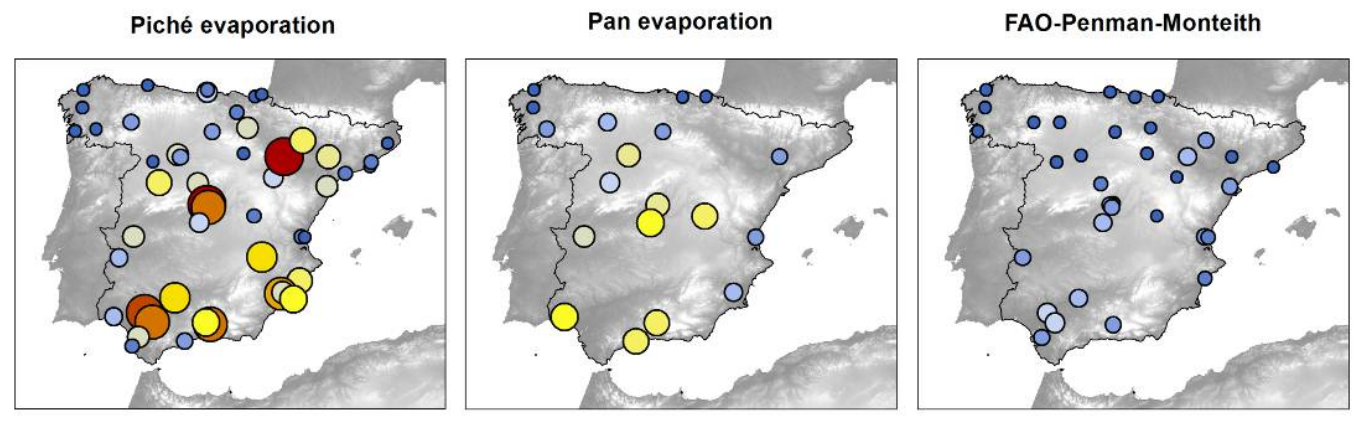

mm/year

- < 1100

- $1100-1200$

- 1200-1300

O 1300-1400

O $1400-1500$
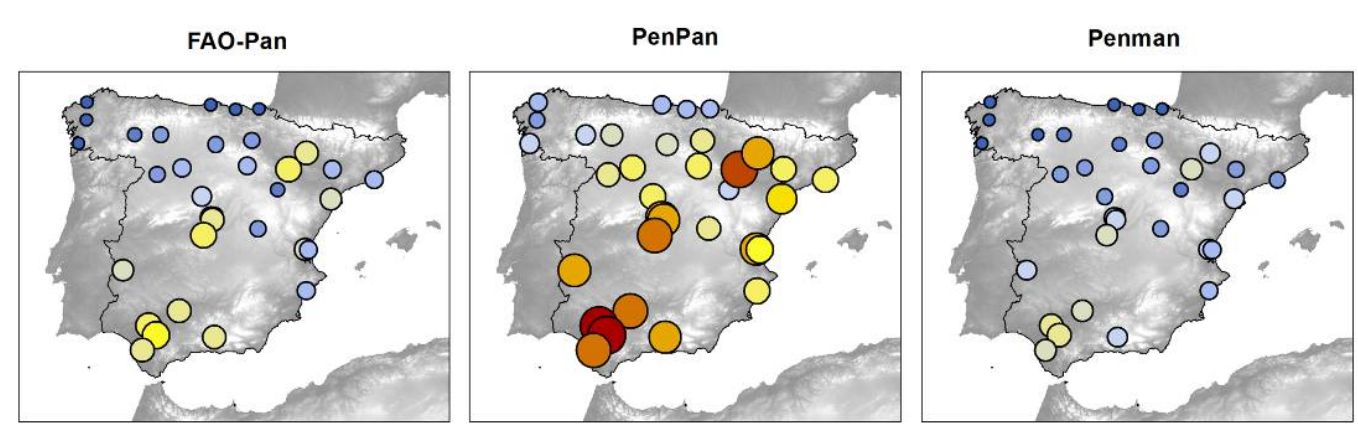

(1500-1600

(1600-1700

(1700-1800

1800-1900

1900-2000

2000-2100

2100-2200

2200-2300

$>2300$

Supplementary Fig. 4. Spatial distribution of annually integrated observed Piché (1961-2011), Pan (1984-2011) and evaporation estimates (1961-2011) using the four physical models. 

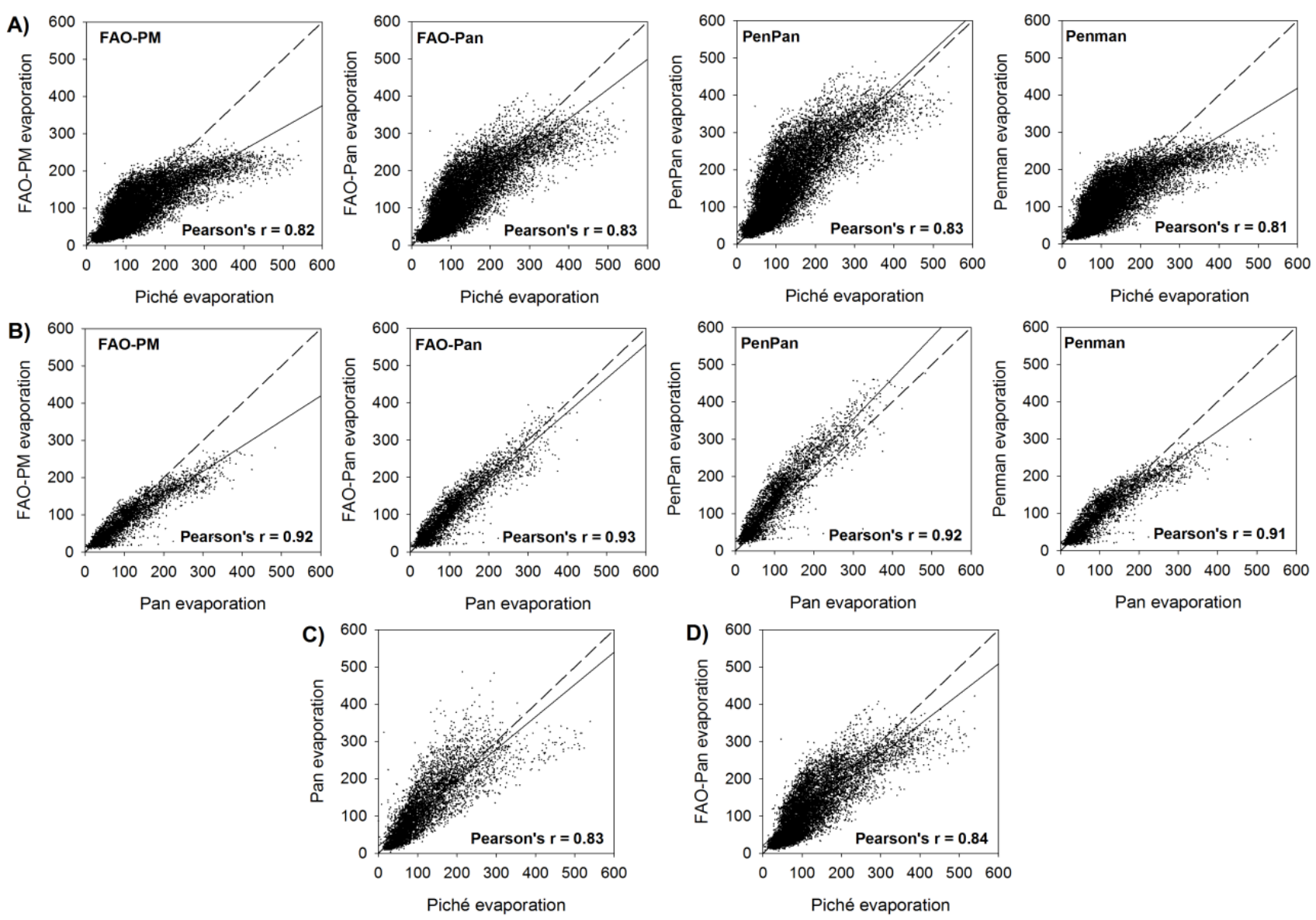

Supplementary Fig. 5. A) Relationship between the monthly observations of Piché evaporation and evaporation estimates at 32 meteorological stations for 1961-2011. B) Relationship between the monthly observations of Pan evaporation and evaporation estimates at 12 meteorological stations for 1984-2011. C) Relationship between the monthly observations of Piché and Pan evaporation at 19 meteorological stations for 1984-2011. D) Relationship between the monthly observations of Piché evaporation and evaporation estimates by FAO-Pan at 32 meteorological stations for 1984-2011. 

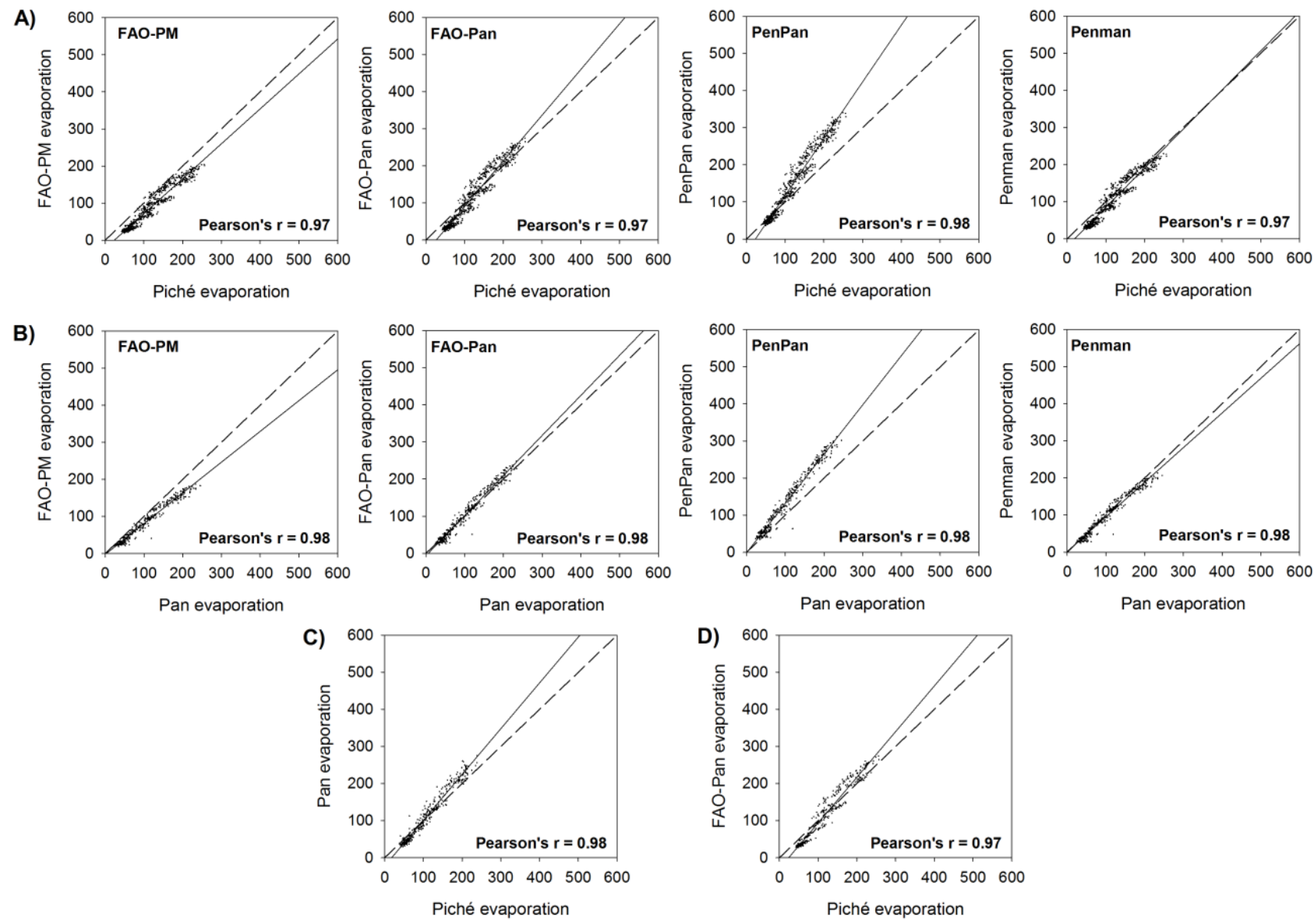

Supplementary Fig. 6. A) Relationship between the monthly observations of Piché evaporation and evaporation estimates by the four methods in the regional series for 1961-2011. B) Relationship between the monthly observations of Pan evaporation and evaporation estimates by the four methods in the regional series for 1984-2011. C) Relationship between the monthly observations of Piché and

Pan evaporation in the regional series for 1984-2011. D) Relationship between the monthly observations of Piché evaporation and evaporation estimates by FAO-Pan in the regional series for 1984-2011. 

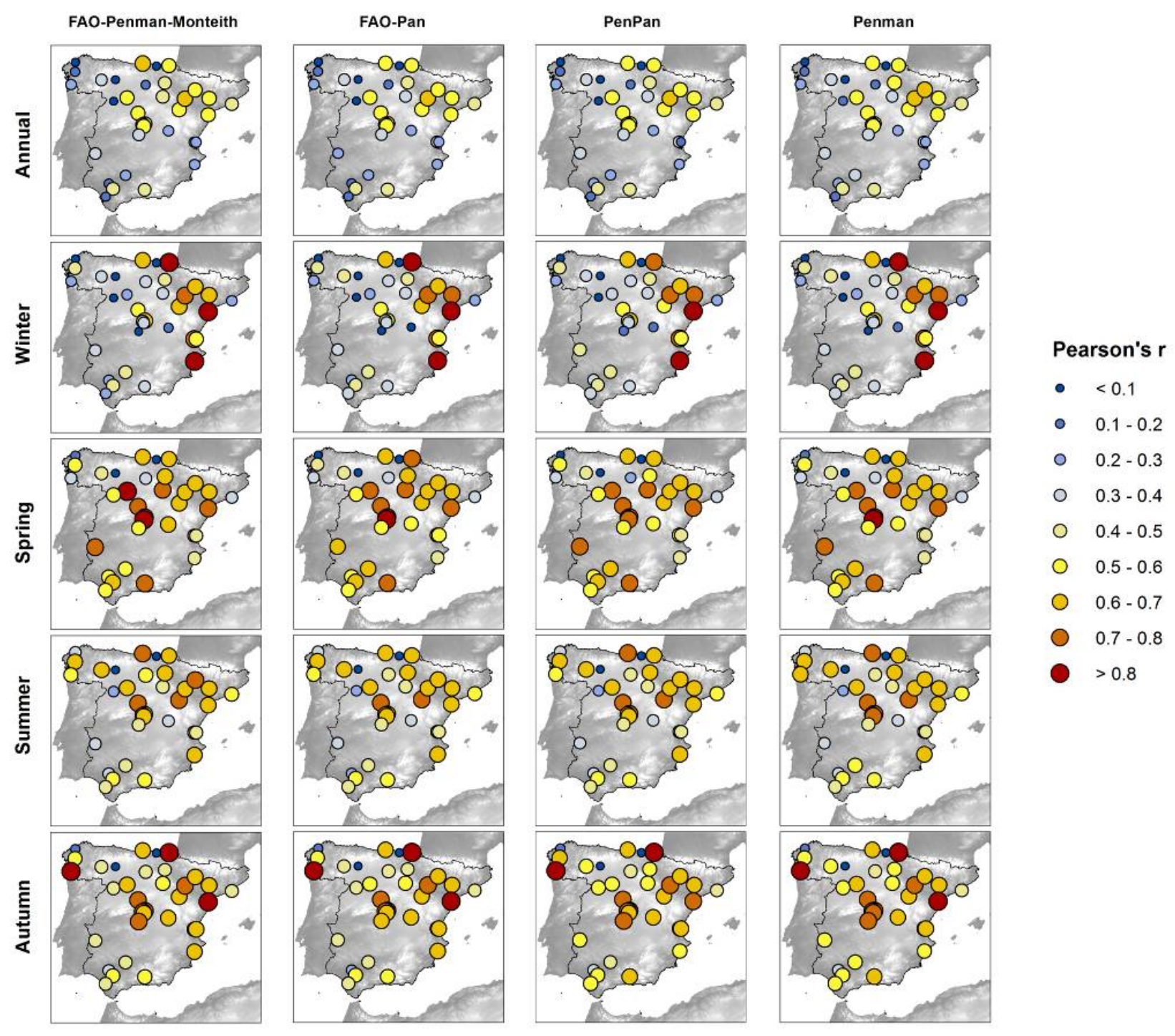

Supplementary Fig. 7. Spatial distribution of Pearson's r correlations between observed Piché evaporation series and the evaporation estimates using four different physical models (1961-2011). 

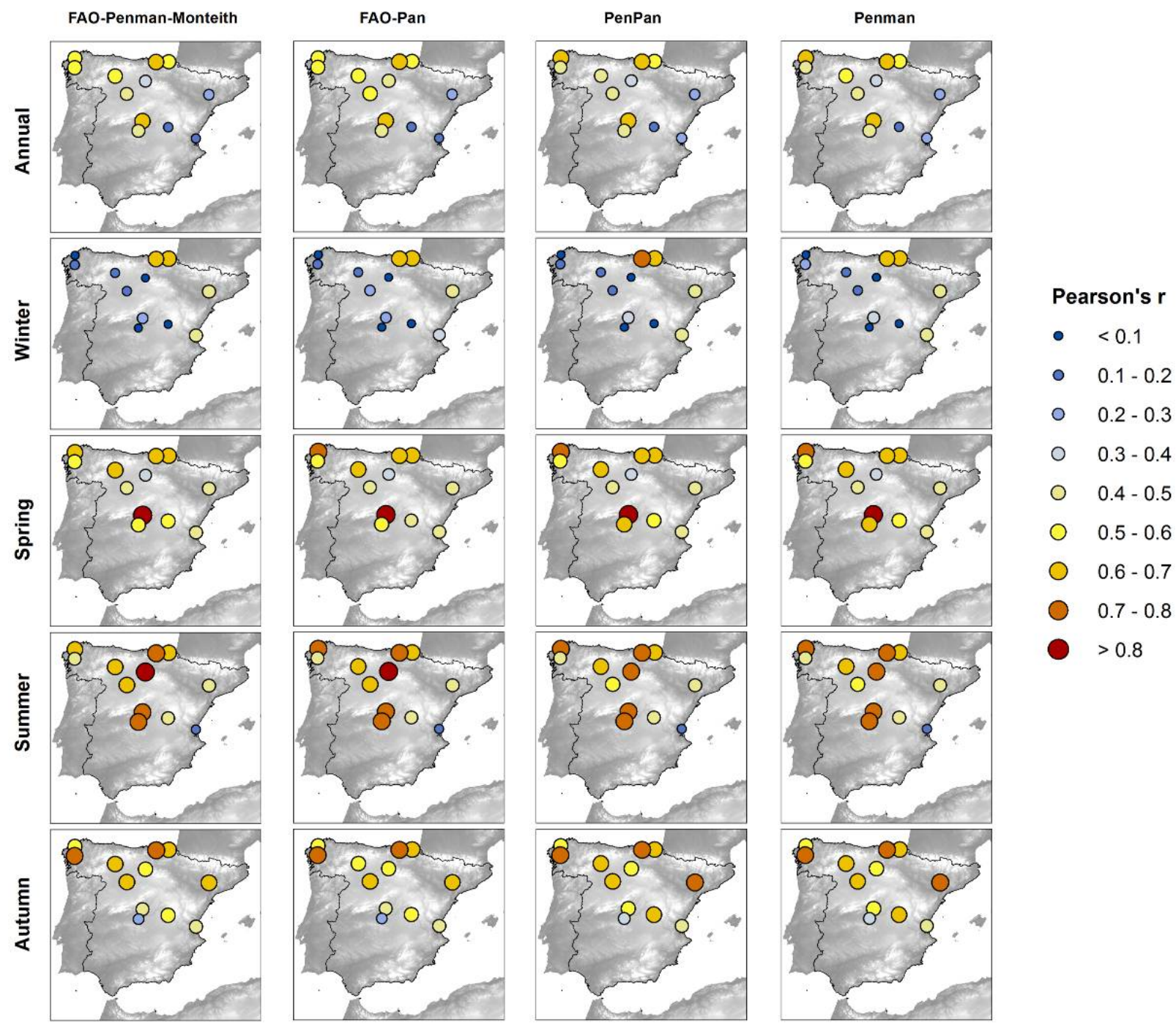

Supplementary Fig. 8. Spatial distribution of Pearson's r correlations between observed Pan evaporation series and the evaporation estimates using four physical models (1984-2011). 

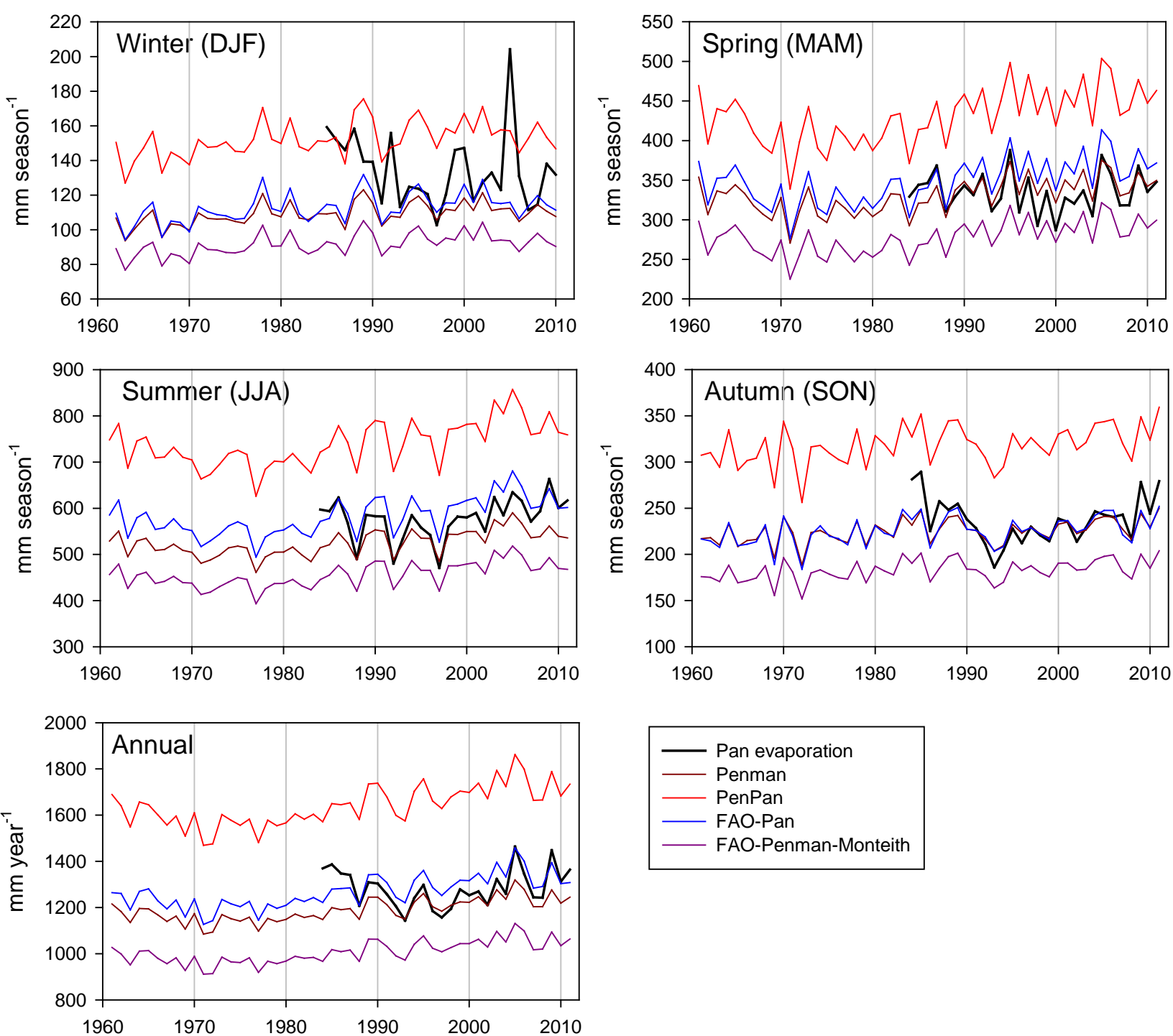

Supplementary Fig. 9. Evolution of the Spanish annual and seasonal average of Pan evaporation (1984-2011) and the evolution of evaporation estimates (1961-2011) by four physical models. 


\section{Piché}

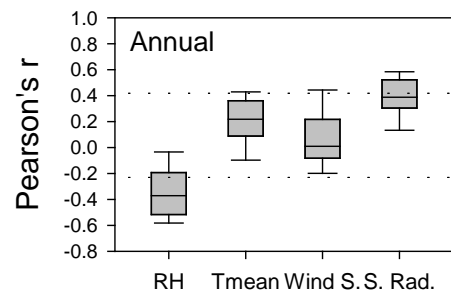

RH Tmean Wind S.S. Rad.

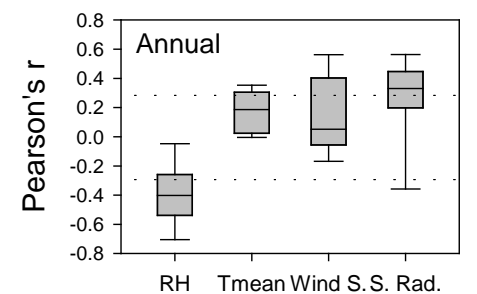

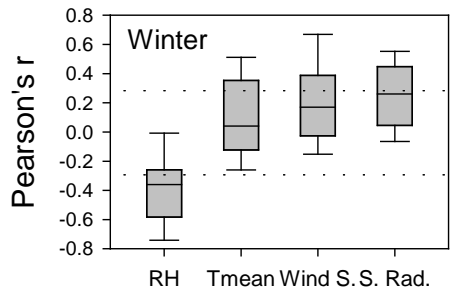

RH Tmean Wind S.S. Rad.

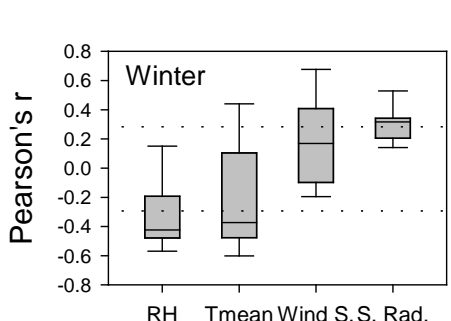

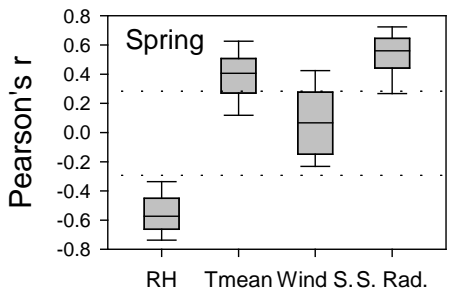

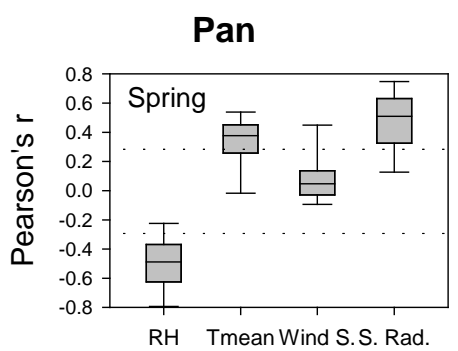

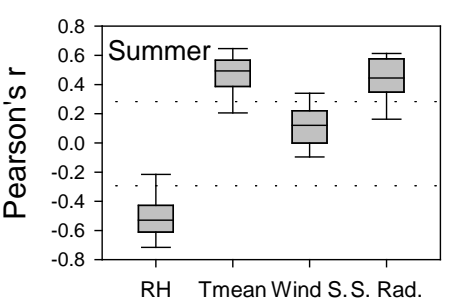

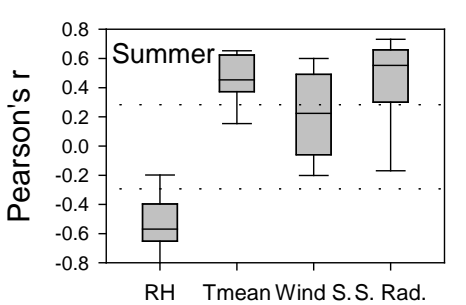

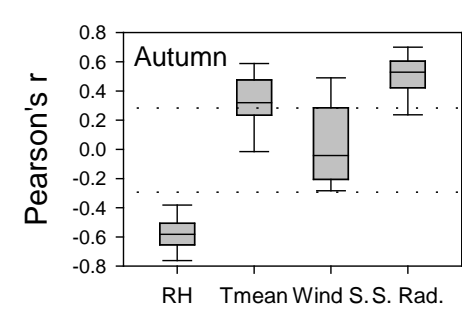

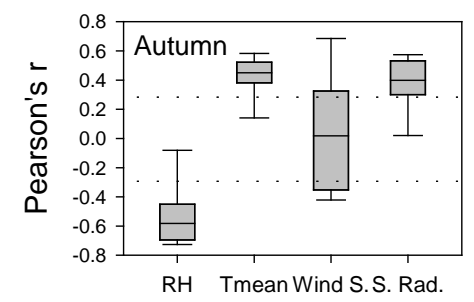

Supplementary Fig. 10. Top row: Box-and-whisker plots of correlations between annual and seasonal Piché evaporation and the four key meteorological variables across 30 stations across Spain for 1961-2011. Bottom row: Box-and-whisker plots of correlations between annual and seasonal Pan evaporation and different climate variables in each one of the 21 stations across Spain for 1984-2011. The mean (middle horizontal line) value, the 25th and 75th percentile range (boxes), and the 10th and 90th (whiskers) are represented. 

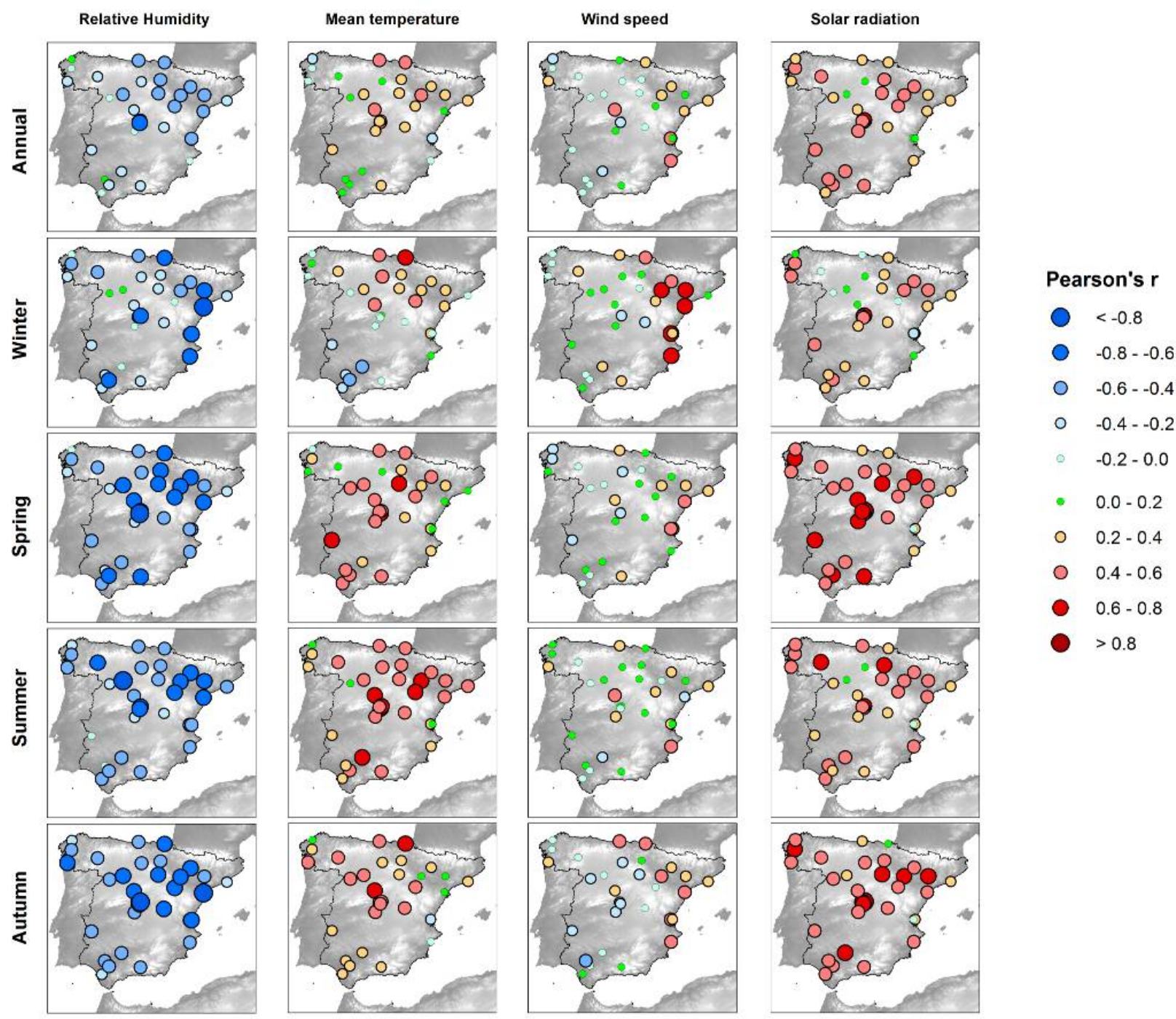

Supplementary Fig. 11. Spatial distribution of annual and seasonal Pearson's r correlation between observed Piché evaporation and four key climate variables (1961-2011). 

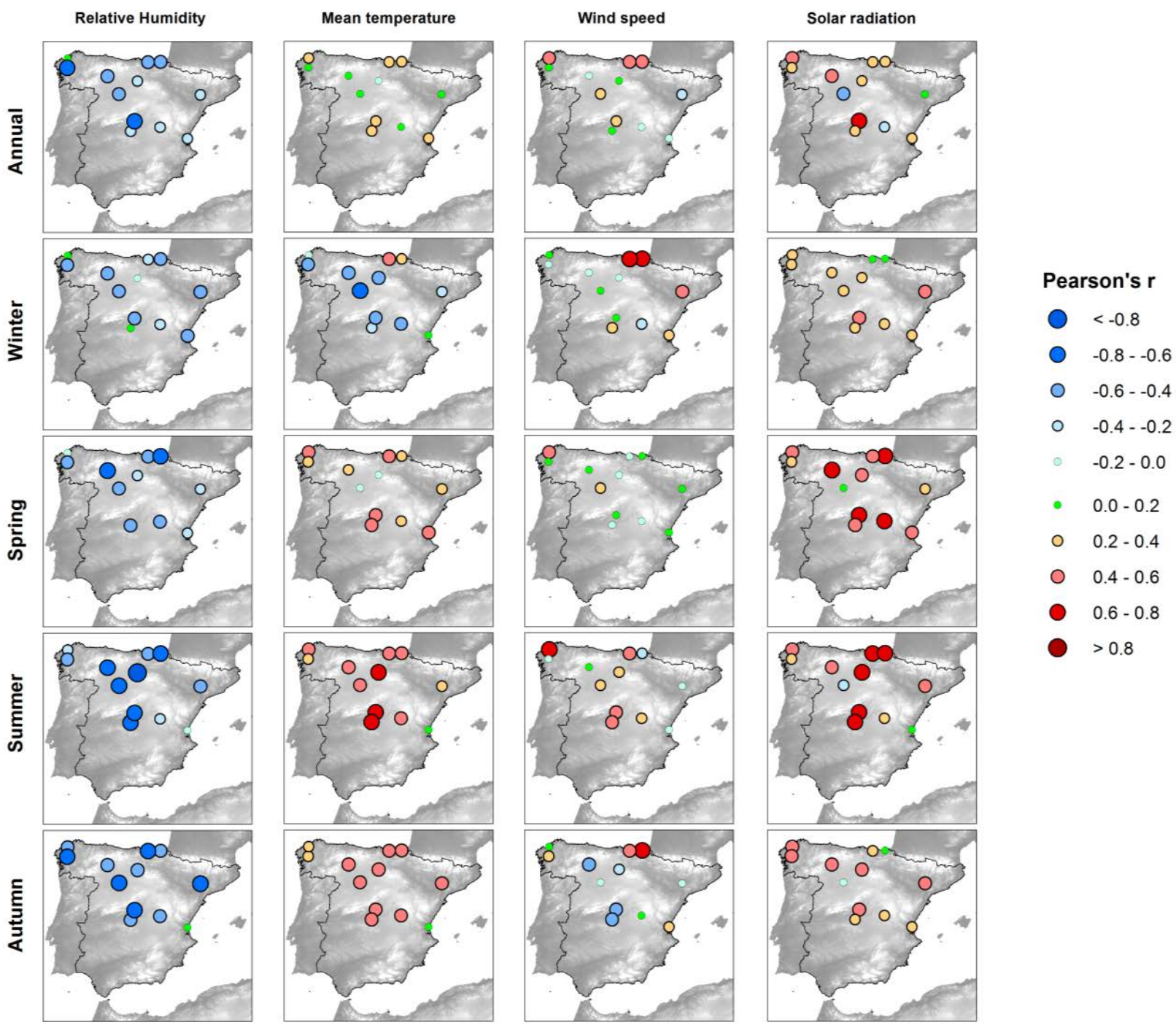

Supplementary Fig. 12. Spatial distribution of annual and seasonal Pearson's r correlation between observed Pan evaporation and four key climate variables (1984-2011). 

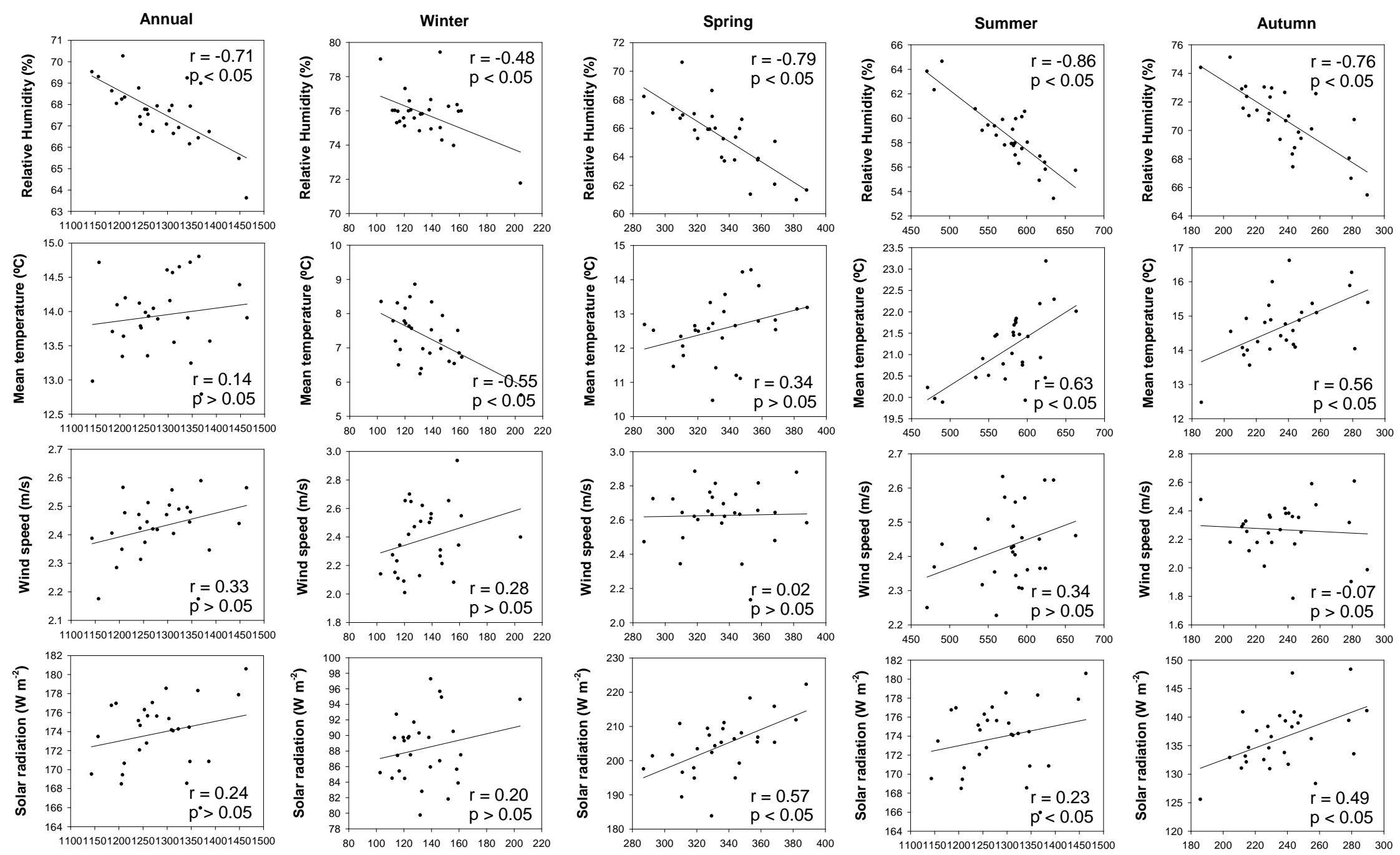

Pan evaporation

Pan evaporation

Pan evaporation

Pan evaporation

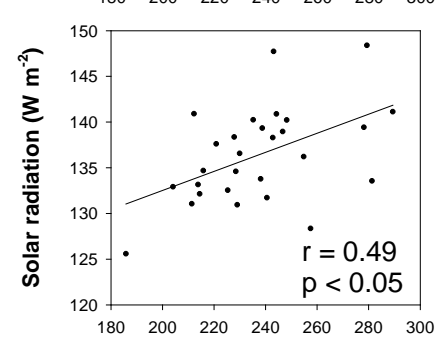

Pan evaporation

Supplementary Fig. 13. Relationship between temporal variability of annual and seasonal regional Pan evaporation and series of four key climate variables (1984-2011). 

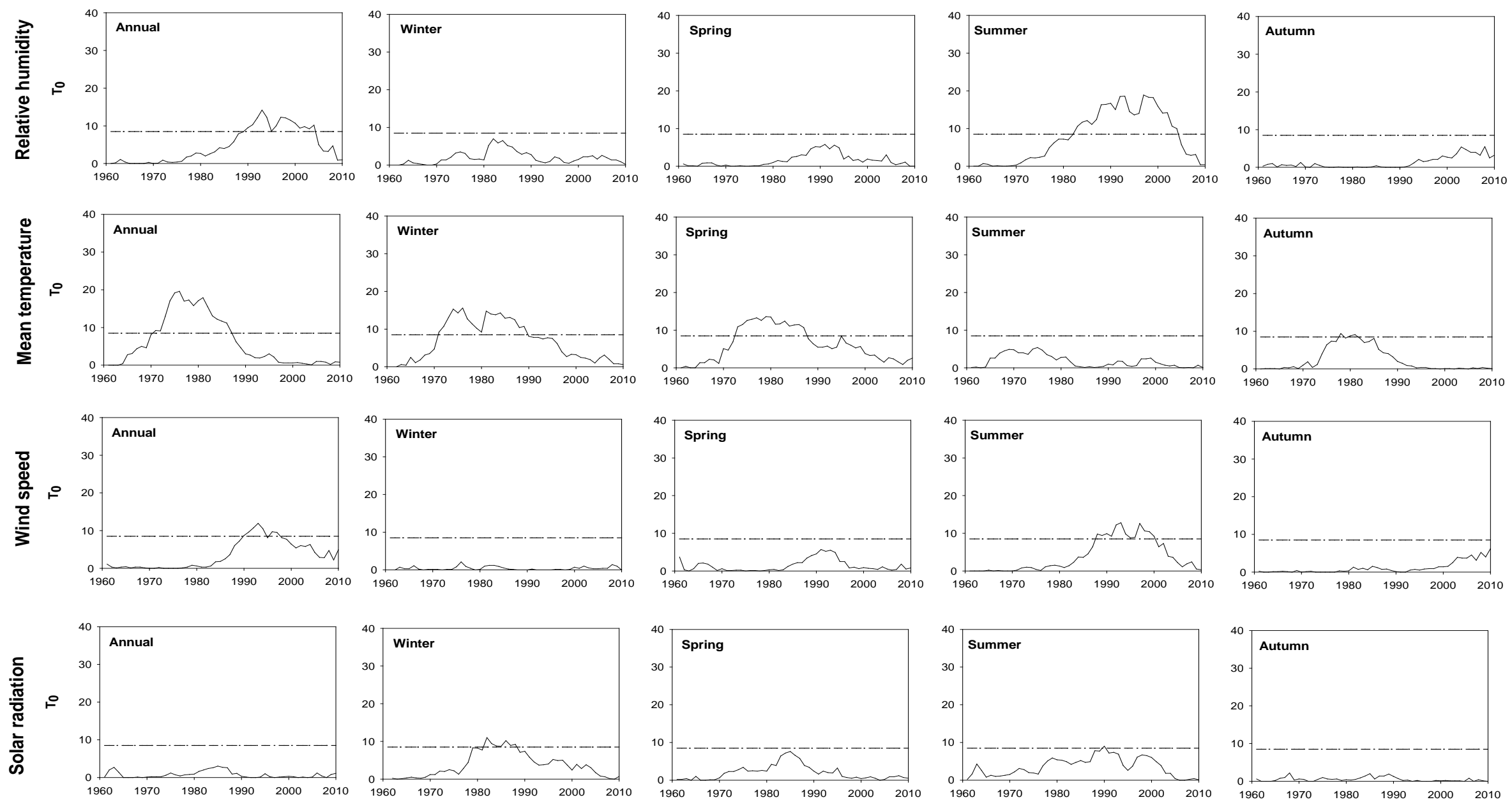

Supplementary Fig. 14. Evolution of the SNHT statistic, $\mathrm{T}_{0}$, for the annual and seasonal series of Piché evaporation considering, in turn, the relative humidity, mean temperature, wind speed and solar radiation series as reference for 1961-2011. Dashed line indicates the signification threshold $(p<0.05)$. 